Revista Temas Socio Jurídicos Vol. $36 \mathrm{~N}^{\circ} 72$ Enero - Junio de 2017

pp. $229-276$

ISSN 0120-8578

ISSN electrónico: $2590-8901$

\title{
LA TRANSVERSALIDAD DE LA IGUALDAD DE GÉNERO Y LA PROMOCIÓN DE CONDICIONES JUSTAS EN EL TRABAJO: REVISIÓN DE INSTRUMENTOS Y POLÍTICAS PROMOVIDAS POR LA OIT
}

\section{J. Eduardo López Ahumada*}

Recibido: Mayo 16 de 2017

Aprobado: Junio 10 de 2017

\section{RESUMEN}

La transversalidad de la igualdad de género (gender mainstreaming) implica la adopción de un conjunto de medidas, políticas y actuaciones en diferentes ámbitos, como el acceso al empleo, la formación académica y profesional, la promoción profesional, las condiciones de trabajo y las medidas de protección social. Ello significa que el objetivo de la igualdad de género tendrá carácter expansivo en las acciones de la Organización Internacional del Trabajo, OIT, y, por supuesto, en las políticas sociales de los Estados miembros, que tendrán que velar por impulsar el cumplimiento de la paridad entre sexos. Igualmente, vamos a tener oportunidad de comprobar el carácter multidisciplinar de la materia, que abarca aspectos no solamente jurídicos, sino también económicos, políticos y sociológicos.

Las mujeres han experimentado en los últimos años un mayor protagonismo en términos de participación en el empleo. La denominada tasa de participación femenina en la fuerza de trabajo ha aumentado con carácter general, aunque la crisis económica y financiera ha interrumpido dicho proceso. Con todo, esta mayor presencia en el mercado de trabajo no ha venido acompañada de medidas de lucha contra las manifestaciones del trabajo precario y, sobre todo, no se ha buscado una efectiva paridad en las condiciones laborales. Las políticas de reducción de las diferencias de género han permitido aumentar las oportunidades de empleo de las mujeres y ello les facilita seguir avanzando en el 
cumplimiento de condiciones laborales análogas y el justo desarrollo de la promoción profesional.

Palabras clave: igualdad de género, principio de no discriminación, precariedad laboral, inseguridad en el empleo, conciliación de las responsabilidades familiares y laborales, OIT

\title{
TRANSVERSALITY OF GENDER EQUALITY AND THE PROMOTION OF FAIR WORKING CONDITIONS: REVIEW OF INSTRUMENTS AND POLICIES PROMOTED BY THE ILO
}

\begin{abstract}
The mainstreaming of gender equality supposes the adoption of a set of measures, policies and actions in different areas, such as access to employment, academic and job training, career promotions, working conditions and social protection measures. This means that the objective of gender equality will be expansive in the actions of the ILO and, Member States will have to ensure the achievement of gender parity within their social policies. Likewise, we will have an opportunity to verify the multidisciplinary nature of this subject, which not only covers juridical, but also economic, political and sociological aspects. Over the last years, women have been more protagonists in terms of participation in employment. The so-called female participation rate in the labor force has generally increased, although the economic and financial crisis has interrupted this process. However, this major presence in the labor market has not been accompanied by measures to combat precarious work and, above all, no effective parity has been sought as far as working conditions are concerned. Policies to reduce gender differences have made it possible to increase women's employment opportunities, making it easier to advance in the fulfillment of similar working conditions and the fair achievement of career promotions.
\end{abstract}

Key words: Gender equality, Principle of non-discrimination, job insecurity, reconciliation of work and family responsibilities

\section{TRANSVERALIDADE DA IGUALDADE DE GÉNERO E A PROMOÇÃO DAS CONDIÇÕES JUSTAS NO TRABALHO: REVISÃO DOS INSTRUMENTOS E POLÍTICAS PROMOVIDAS PELA OIT}


A transversalidades da Igualdade do género (gender mainstreaming) envolve tomar uma série de medidas, políticas e ações em diferentes áreas, tais como o acesso ao emprego, à formação acadêmica e profissional, a promoção profissional, as condições de trabalho e as medidas de proteção social. Isto significa que o objetivo da igualdade de gênero será expansionista nas ações da OIT e, naturalmente, nas políticas sociais dos Estados-Membros, que terá de assegurar a promoção do cumprimento da paridade de gênero. Além disso, teremos a oportunidade de verificar a natureza multidisciplinar do tema, abrangendo aspectos não só jurídicos, mas também econômicos, políticos e sociológicos.

As mulheres têm experimentado nos últimos anos um papel maior em termos de participação no emprego. A chamada taxa de participação feminina na força do trabalho aumentou em geral, embora a crise económica e financeira interrompeu esse processo. No entanto, este aumento da presença no mercado laboral não foi acompanhado de medidas para combater manifestações de trabalho precário e, acima de tudo, não tenha sido solicitada efetiva igualdade nas condições laborais. As políticas de redução de diferenças de gênero têm aumentado as oportunidades de emprego das mulheres, e deve facilitar o progresso no cumprimento de condições de trabalho semelhantes e o desenvolvimento justo da promoção profissional.

Palavras-chave: Igualdade de gênero, princípio de não discriminação, precariedade laboral, insegurança no emprego, conciliação das responsabilidades familiares e laborais, OIT.

\section{NUEVAS FÓRMULAS DE PROTECCIÓN DE LA DISCRIMINACIÓN POR RAZÓN DE GÉNERO: RECONOCIMIENTO DEL PRINCIPIO DE NO DISCRIMINACIÓN}

La discriminación por razón de sexo está presente en las relaciones laborales y las mujeres siguen sufriendo prácticas discriminatorias en el acceso al empleo, las retribuciones, las condiciones laborales o las prestaciones sociales. Y ello a pesar de la evolución de los sistemas normativos que contemplan nuevas medidas que intentar evitar las diferencias salariales, la segregación profesional y el fomento de la conciliación del trabajo y la vida familiar y personal. Con todo, la OIT sigue contemplando en sus programas de actuación el objetivo de conseguir que el derecho fundamental de no discriminación en el 
empleo y la ocupación, se convierta en un principio rector de las políticas legislativas de los Estados, así como criterio informador de la práctica administrativa como medio para conseguir una sociedad más justas.

La supresión de la discriminación en el trabajo forma parte de los propios principios constitutivos de la OIT desde su creación en 1919. La propia Declaración de Filadelfia de 1944, así como la Declaración de la OIT relativa a los principios y derechos fundamentales en el trabajo de 1998 conceden el máximo reconocimiento a la igualdad por razón de sexo, al contemplarse el compromiso de eliminar cualquier tipo de discriminación en el empleo y la ocupación [punto 2, letra d)] ${ }^{1}$. Especialmente importante es el Convenio OIT núm. 111 sobre discriminación en el empleo y ocupación, de 25 de junio de $1958^{2}$, que alude a la discriminación como "cualquier distinción, exclusión o preferencia basada en motivos de raza, color, sexo, religión, opinión política, ascendencia nacional $\mathrm{u}$ origen social que tenga por efecto anular o alterar la igualdad de oportunidades o de trato en el empleo y la ocupación" [art. 1, a)]. Esta declaración tiene igualmente proyección específica en materia de discriminación salarial por razón de género, ya que el Convenio OIT núm. 100, sobre igualdad de remuneración de 29 de junio de 1951, contempla expresamente el derecho a la "igualdad de remuneración entre la mano de obra masculina y la mano de obra femenina por un trabajo de igual valor" [art. 1,b].

Precisamente, dicho reconocimiento internacional ha sido calificado tradicionalmente como insuficiente a los efectos de eficacia jurídica. Ello se debe esencialmente al bajo nivel de coercibilidad que tienen las normas internacionales, lo cual supone que el binomio trabajo decente e igualdad de género se presenta como un mecanismo de soft-law internacional, que pretende generar un contexto normativo de referencia que anime a los Estados miembros a contemplar dichas normas en sus sistemas jurídicos-laborales. En este sentido, el art. 22 de la Constitución de la OIT obliga a cada uno de los Estados miembros a "presentar a la Oficina Internacional del Trabajo una memoria anual sobre las medidas que haya adoptado para poner en ejecución los convenios a los cuales se haya adherido" ${ }^{3}$. De igual modo, los Estados

1. Declaración formulada en el marco de la $86^{a}$ reunión de la Conferencia Internacional del Trabajo, Ginebra, 18 de junio de 1998. En este mismo sentido, cobra especial importancia en materia de reconocimiento del principio de no discriminación la Declaración de la OIT sobre justicia social para una globalización equitativa de 2008 y el Pacto Mundial para el Empleo de 2009.

2. Según datos de la OIT, el Convenio núm. 111 ha sido ratificado por 168 Estados miembros, siendo el quinto convenio más ratificado de la OIT.

3. A estos efectos, el seguimiento de la Declaración se basa en las memorias solicitadas a los Estados Miembros en cumplimiento del apartado e) del párrafo 5 del artículo 19 de la Constitución de la OIT, en el que se establece el procedimiento de información acerca de los convenios fundamentales no ratificados. 
están obligados a "informar sobre el estado de [su] legislación y la práctica en lo que respecta a los asuntos tratados en el convenio, precisando en qué medida se ha puesto o se propone poner en ejecución cualquiera de las disposiciones del Convenio e indicando las dificultades que impiden o rechazan la ratificación de dicho Convenio" ${ }^{4}$.

La discriminación en el empleo y la ocupación por razón de género conlleva ciertamente un trato diferente y menos favorable sin atender a los méritos ni a la cualificación de la mujer trabajadora para el desarrollo del trabajo. Ello supone efectivamente un supuesto de disfavor que se fundamenta únicamente en razones de sexo. Estamos, pues, ante la merma de las oportunidades laborales y se restringe la libertad de trabajo y el libre desarrollo de las aptitudes y cualidades, así como la justa retribución por el trabajo desarrollado. En este sentido, la discriminación por razón de sexo en el trabajo es un claro ejemplo de vulneración de un derecho humano ${ }^{5}$ y tiene efectos sociales perjudiciales, ya que impide el desarrollo de condiciones equitativas y entraña un coste económico y social. Se trata de condiciones que dificultan el objetivo del trabajo decente ${ }^{6}$, ya que si no se supera esta situación no se puede erradicar la pobreza ni los márgenes de exclusión social. Incluso, desde el punto de vista empresarial, el fomento de los supuestos de no discriminación puede repercutir positivamente en la productividad en el trabajo y aumentar el bienestar en la empresa, lo cual significa que ciertamente pueden ser aplicadas en beneficio de la propia empresa.

\section{FENÓMENOS DE DISCRIMINACIÓN DE GÉNERO Y PRINCIPALES MANIFESTACIONES EN LAS RELACIONES LABORALES}

Si tenemos en cuenta el concepto de discriminación del Convenio núm. 111 , podemos afirmar que la voluntad es reforzar la tutela de la situación

4. En este punto, destaca la respuesta de la OIT en su asistencia a los Estados miembros con el fin de eliminar la discriminación en el empleo y la ocupación. Vid. OIT: Seguimiento de la Declaración de la OIT relativa a los principios y derechos fundamentales en el trabajo: prioridades y programas de acción para la cooperación técnica relativa a la eliminación de la discriminación en materia de empleo y ocupación. Informe de la Comisión de Cooperación Técnica. Documento GB.300/TC /4, Consejo de Administración, 300. ${ }^{\mathrm{a}}$ reunión, Ginebra, noviembre de 2007.

5. Sin duda, el reconocimiento como derecho fundamental tiene especial acogida en la doctrina del TJCE. Según esta doctrina la prohibición de discriminación por razón de sexo ha dejado de ser un principio de la política económica para configurarse en un verdadero derecho fundamental a la igualdad de trato entre hombres y mujeres. Vid. PÉREZ DEL RÍO, Mª.T., "El principio de igualdad de trato y la prohibición de discriminación por razón de sexo en el derecho comunitario", en Cuadernos de Derecho Judicial, núm. 10, 1997, pp. 51-52. BALLESTER PASTOR, Ma .A., "El principio comunitario de igualdad de trato por razón de origen racial o étnico", en Revista del Ministerio de Trabajo e Inmigración, núm. 63, 2006, pp. 35-36. Por su parte, destacan los arts. 6-8 de la Directiva 2002/73, que contempla reglas en relación a acciones y medidas que impulsan la igualdad de género y facilitan el control de los comportamientos discriminatorios, medidas estas ya contempladas por el TJCE. Vid., por ejemplo, Asuntos Draehmpaehl ( STJCE de 22 de abril de 1997 [ TJCE 1997, 82], C-180/95) y Coote (STJCE de 22 de septiembre de 1998 [ TJCE 1998, 207], C-185/97). 6. Vid. FAUROUX, R., La lutte contre les discriminations dans le domaine de l'emploi, Ministerio de Empleo, Cohesión Social y Vivienda, París, 2005. 
de desventaja de determinados colectivos, entre ellos las mujeres, en el trabajo y se intenta perseguir los comportamientos discriminatorios en todas sus etapas, esto es, en la búsqueda del empleo, en la dinámica de las relaciones laborales o en el momento de la extinción del contrato de trabajo. De igual modo, esta declaración tiene carácter expansivo, ya que no solo afecta al trabajo declarado, objeto de protección jurídicolaboral y social, sino que también incide en el trabajo informal. Precisamente, porque esta tipología de trabajo se configura como un subterfugio que da lugar a situaciones de discriminación y de elusión de la protección social ${ }^{7}$.

Tradicionalmente, las prácticas de discriminación se manifiestan de forma directa o indirecta, siguiendo su conceptualización clásica. Ciertamente, las discriminaciones directas son más evidentes y suponen la exclusión o preferencia de determinadas personas pertenecientes a un determinado colectivo (por ejemplo, la exclusión por rebasar una determinada edad o encontrarse en una franja de edad coincidente con las etapas de maternidad). Sin duda, más compleja es la situación de la discriminación indirecta, ya que se trata de normas o prácticas que se configuran formalmente como neutras desde el punto de vista del género, pero que en la práctica dan lugar a efectos discriminatorios en el colectivo de las mujeres (por ejemplo, la organización de cursos de formación fuera del horario de trabajo al que generalmente no se suman las mujeres que se encargan de las labores domésticas). Dichas discriminaciones indirectas ocasionan ciertamente problemas de trato diferenciado en determinadas categorías profesionales, dando lugar a diferencias salariales, de jornada o la imposibilidad de acceder a determinadas prestaciones sociales o percibirlas con una menor protección. La OIT ha prestado especial atención a la supresión de las discriminaciones de naturaleza estructural, que están presentes en los ordenamientos jurídicos y en las prácticas judiciales y administrativas de los Estados. Este tipo de discriminaciones perpetúa las situaciones e impide la promoción del trabajo digno para las mujeres trabajadoras. Dichas prácticas discriminatorias se aprecian sobre todo en países de economías emergentes o en vías de desarrollo y se refieren especialmente al tratamiento de minorías étnicas o extranjeros.

\footnotetext{
7. En estos casos emergen nuevas situaciones y realidades sociales que tienen por finalidad eludir dicha protección al encontrarse fuera del campo o ámbito de aplicación de la legislación laboral y de sus mecanismos tradicionales de cumplimiento efectivo.

8. En la Directiva 2002/73 se contempla una definición de discriminación directa e indirecta, por razón de sexo, en los siguientes términos: "Discriminación directa": la situación en que una persona sea, haya sido o pudiera ser tratada de manera menos favorable que otra en situación comparable por razón de sexo. Discriminación indirecta: la situación en que una disposición, criterio o práctica aparentemente neutros sitúan a personas de un sexo determinado en desventaja particular con respecto a personas del otro sexo, salvo que dicha disposición, criterio o práctica pueda justificarse objetivamente con una finalidad legítima y que los medios para alcanzar dicha finalidad sean adecuados y necesarios" (art. 2.2).
} 
Con todo, es preciso distinguir las discriminaciones por motivos de género de supuestos de trato diferenciado plenamente justificados, que no se pueden considerar prácticas discriminatorias. Por ejemplo, debido a la formación académica o profesional, la experiencia o la polivalencia funcional, factores de carácter objetivo que permiten diferencias de trato en el empleo y la ocupación plenamente procedentes debido a la concurrencia de méritos personales (aptitudes, conocimientos y cualificaciones, así como requisitos para el desarrollo del trabajo) ${ }^{9}$. Se trata, en definitiva, de factores que permiten individualizar las situaciones respecto de una persona, que se muestra idónea para ocupar dicho puesto de trabajo, de modo que no concurre discriminación indirecta cuando la medida resulta justificada en sus objetivos como en la proporcionalidad de sus medios. Con todo, los problemas en la práctica se generan a la hora de evaluar dichos méritos y de determinar su concurrencia entre varios trabajadores y trabajadoras con el fin de buscar al candidato mejor cualificado. Otros factores ciertamente tendrían en principio que generar menos problemas en la práctica y se refieren a las diferencias laborales por motivos de polivalencia, destreza profesional, mayor esfuerzo, horas trabajadas, peligrosidad del trabajo, antigüedad, etc., aspectos que permiten tratos diferentes que son plenamente legítimos.

En otros casos, la aplicación del principio de igualdad de género implica avanzar y desmarcarse de las inercias, ya que un tratamiento igualitario puede generar situaciones injustas. Por ello, no son discriminatorias las medidas de naturaleza especial que tienen por objetivo dar un trato diferenciado hacia quienes presentan necesidades específicas por razones de género. Se trata de medidas especiales que permiten adaptar las situaciones en términos de justicia, por ejemplo, medidas de refuerzo de la protección de las trabajadoras durante el embarazo y el puerperio, con el fin de conseguir una verdadera igualdad en relación a los hombres. Son acciones positivas o afirmativas, que se configuran como medidas especiales de carácter temporal que permiten acelerar la mejora de las condiciones de trabajo de las mujeres removiendo la situación de discriminación que han venido sufriendo. Ello está en clara sintonía con la denominada estrategia dual, que combina las medidas de acción positiva con la perspectiva de género.

\footnotetext{
9. Respecto de los problemas jurídicos derivados de la aplicación del principio de igualdad y no discriminación y la posibilidad de trato diverso en las relaciones laborales. Vid. GARCÍA MURCIA, J., "Igualdad y no discriminación en las relaciones laborales", Las transformaciones del Derecho del Trabajo en el marco de la Constitución Española, Estudios en homenaje al profesor M. Rodríguez-Piñero y BravoFerrer, La Ley, Madrid, 2006, pp. 399-405.
} 


\section{LA CONCURRENCIA DE LA DESIGUALDAD DE GÉNERO CON OTRAS FORMAS DE DISCRIMINACIÓN : DISCRIMINACIÓN MÚLTIPLE}

Las formas de discriminación de género han ido evolucionando con el paso del tiempo y actualmente podemos hablar de un contexto ciertamente heterogéneo que afecta especialmente a la mujer trabajadora. Ello implica que las mujeres trabajadoras tienen derecho a disfrutar de un trabajo decente, sin perjuicio de su nacionalidad, raza, religión, origen social ${ }^{10}$, edad ${ }^{111}$, discapacidad, orientación sexual, etc. Se trata de un tema profundamente complejo, donde están presentes múltiples aspectos jurídicos. En la práctica resulta difícil diferenciar la discriminación fundada en el sexo de aquellos supuestos discriminatorios basados en la raza o en el origen nacional, y ello debido a que, por ejemplo, sexo y raza o ascendencia nacional son factores indisolublemente relacionados, que afectan concretamente a colectivos con identidades culturales propias de minorías sociales.

La discriminación por motivos de género no se presenta en la realidad como un fenómeno unívoco y estático, puesto que generalmente concurre con otros motivos discriminatorios que son difíciles de erradicar en la práctica por motivos sociales e incluso culturales. Ello supone que ser mujer trabajadora y, por ejemplo, inmigrante aumenta considerablemente las probabilidades de sufrir prácticas discriminatorias, lo cual es una desventaja en el trabajo. ${ }^{12}$ Ello es reflejo de prácticas racistas debido a los prejuicios existentes ante los trabajadores extranjeros, cuyos efectos han aumentado por la crisis del empleo y por los peligros de la globalización. De este modo, la mujer trabajadora se encuadraría en un colectivo social que encuentra especiales dificultades de ejercicio del libre desarrollo personal y profesional.

Junto a los motivos de nacionalidad, podemos destacar la situación de las mujeres indígenas u otras minorías sociales que se encuentran excluidas del

10. La discriminación por motivos de origen social implica que la mujer trabajadora se ve relegada del trabajo debido a su pertenencia a una clase social o casta que condiciona su situación laboral y le impide su desarrollo profesional.

11. Especialmente preocupante es la situación de las mujeres jóvenes a quienes les resulta más difícil encontrar un trabajo adecuado en determinadas profesiones y ello a pesar de finalizar su educación o formación. Vid. OIT: Tendencias mundiales del empleo juvenil, publicación especial sobre la incidencia de la crisis económica global en los jóvenes, Ginebra, agosto de 2010, p. 12.

12. Los trabajadores migrantes pueden sufrir discriminaciones por motivos de su raza, religión real o supuesta, y ello junto al factor de ser inmigrantes. La protección de los intereses de los trabajadores empleados en el extranjero ha sido una preocupación constante para la OIT. Con ello se pretende solucionar problemas derivados de la intensificación de los flujos migratorios, que ha hecho que las sociedades sean más diversas. Ya en la Conferencia Internacional del Trabajo 2004 se incluyó la situación de los trabajadores migrantes como tema de discusión general. Vid. CRUSH, J. - RAMACHANDRAN, S., Xenophobia, international migration and human development, Human Development Research Paper, 2009/47, PNUD, 2009, p. 31. 
acceso al empleo ${ }^{13}$, así como otros supuestos de discriminación ligados a motivos raciales, culturales y religiosos. En todos estos casos, los problemas son de identidad y de pertenencia de la mujer trabajadora a un colectivo social con graves problemas de acceso al mercado de trabajo. Igualmente, y en atención a la circunstancia personal de la mujer trabajadora, tiene especial proyección la discriminación por motivos de edad (especialmente trabajadoras jóvenes o maduras), por discapacidad o por apariencia de física (por ejemplo, por motivos de obesidad) ${ }^{14} \mathrm{o}$ debido a un concreto estilo de vida. Estos casos de discriminación múltiple requieren de respuestas jurídicas nuevas y adaptadas a los colectivos afectados. ${ }^{15}$ Esta máxima se puede entender contemplada implícitamente en el propio Convenio núm. 111, dada la flexibilidad con la que se pronuncia sobre la no discriminación, de modo que ello permitiría la introducción de nuevos motivos de discriminación prohibidos en las legislaciones. No cabe duda de que la ausencia de referencia a la discriminación múltiple en la legislaciones tiene efectos perjudiciales en términos de protección jurídica. Por ejemplo, los tribunales siguen dando preferencia en sus resoluciones a la evaluación de la discriminación desde la perspectiva de una sola causa discriminatoria y los procesos se desarrollan de forma genérica sin abordar en su integridad la complejidad de los conflictos jurídicos. Ciertamente, es preciso seguir avanzando en el reconocimiento de la discriminación múltiple y en su reflejo progresivo en la práctica jurisdiccional como mejor vía de protección de la discriminación de género.

\section{LA PARTICIPACIÓN DE LAS MUJERES EN EL TRABAJO: ELHÁNDICAP DELACCESO AL EMPLEO}

Las mujeres han experimentado en los últimos años un mayor
protagonismo en términos de participación en el empleo. La

13. En el caso de los pueblos indígenas la situación afecta a un gran colectivo, cercano al cinco por ciento de la población mundial, siendo especialmente relevante la situación en América Latina. El problema tiene efectos no solo en el acceso al empleo sino también en las retribuciones. La OIT tiene convenios específicos sobre los pueblos indígenas (Convenio núm. 169 de 1989). Por su parte, en Europa tiene una especial proyección la situación del pueblo romaní, situación que ha sido destacada por el Centro Europeo de Derecho de los Romaniés, que padecen condiciones de exclusión social y pobreza.

14. Últimamente ha cobrado especial relevancia la discriminación por razón de la apariencia física. Por ejemplo, en EEUU la discriminación por motivos de imagen (peso/estatura) afecta especialmente a las mujeres en el ámbito laboral y son comparables a la discriminación por motivos de raza, edad o sexo. Incluso en países como Francia o Bélgica se han aprobado disposiciones específicas sobre este tipo de discriminaciones. Vid. PUHL, R.M. - ANDREYEVA, T. - BROWNELL, K.D., "Perceptions of weight discrimination: Prevalence and comparison to race and gender discrimination in America", International Journal of Obesity, 2008, núm. 32, pp. 992-1000. ROOTH, D. Evidence of unequal treatment in hiring against obese applicants: A field experiment, Institute for the Study of Labor, mayo de 2007.

15. Desde la Unión Europea, se ha intentado dar respuesta a estos casos de discriminación múltiple. En este sentido, destaca la Directiva 2000/43/CE del Consejo, de 29 de junio de 2000, relativa a la aplicación del principio de igualdad de trato de las personas independientemente de su origen racial o étnico. Por su parte, la Directiva 2000/78/CE del Consejo, de 27 de noviembre de 2000, relativa al establecimiento de un marco general para la igualdad de trato en el empleo y la ocupación, destinada a prohibir la discriminación basada en la religión o el credo, la edad, la discapacidad y la orientación sexual. 
denominada tasa de participación femenina en la fuerza de trabajo ha aumentado con carácter general, aunque la crisis económica y financiera ha interrumpido dicho proceso. Dicha tendencia alcista fue apuntada por la OIT en $2007^{16}$ y ya en este momento se apreciaba cómo los primeros efectos de la crisis económica y financiera en Asia estaban afectando más al empleo femenino en comparación con el masculino. Efectivamente, los datos demuestran que el aumento de la incorporación progresiva de la mujer al mercado de trabajo y su participación en el empleo remunerado no es más que una constatación de una realidad social. No obstante, y a pesar de esta afirmación, la OIT considera que dicho incremento de la participación laboral de las mujeres en el trabajo no se ha aprovechado intensamente y no se han realizado cambios significativos en la calidad en el empleo y, sobre todo, en la distribución de las tareas del hogar que permitan una mejor conciliación del trabajo con la vida familiar y personal.

La mayor presencia en el mercado de trabajo no ha venido acompañada de medidas de lucha contra las manifestaciones del trabajo precario y, sobre todo, no se ha buscado una efectiva paridad en las condiciones laborales, especialmente, las retributivas. Tampoco se han aprovechado en relación al empleo femenino las posibilidades que brindan las nuevas ocupaciones, que permiten una mayor presencia de la mujer en el mundo laboral. Se trata de nuevos trabajos relacionados sobre todo con las posibilidades presentes en las tecnologías de la información y las comunicaciones. Según la naturaleza de dichos trabajos, que tienen un contenido de cualificación importante, la segregación profesional es menos intensa y abre ciertamente nuevos ámbitos de acción al fomento de la igualdad de trabajo y de oportunidades para el empleo femenino.

Sin duda, la formación es un factor clave para garantizar el aumento de la participación de la mujer en el trabajo remunerado. Ciertamente, el objetivo es ambicioso, ya que desde el punto de vista comparado no todos los países han conseguido una igualdad en la matriculación de las mujeres en la educación primaria y secundaria en términos de paridad de género. No obstante, la mayor presencia de la mujer en la formación reglada es un hecho, que se refleja hasta en los propios ciclos universitarios y ello explica ciertamente la mejora de las tasas de participación de la mujer en el trabajo. De este modo, las mujeres con niveles más bajos de educación y formación están más expuestas al riesgo de no poder acceder al trabajo, circunstancia que

16. Vid. OIT, La igualdad en el trabajo: afrontar los retos que se plantean, op. cit., pp. 18-19. Según dicho informe, el aumento fue exponencialmente superior en países de América Latina y el Caribe, seguido de la Unión Europea. En cambio, en Asia Meridional, Oriente Medio y África del Norte el aumento fue menor. 
inevitablemente se agrava en función de la edad. Actualmente estos problemas se agudizan considerablemente en época de recesión, siendo el déficit formativo un índice que implica un mayor riesgo de pérdida del trabajo.

Desde el punto de vista del desempleo, es preciso indicar que sobre todo el paro laboral de larga duración afecta con más intensidad a la mujer, que se presenta como un colectivo desfavorecido. De este modo, la OIT ha recomendado a los Estados intensificar sus acciones por medio de políticas activas en el mercado de trabajo, introduciendo la perspectiva de género de forma transversal en los servicios de búsqueda de empleo. Por tanto, se trata de un principio esencial que gravita en la política de empleo en materias como la colocación, contratación laboral, programas formativos, régimen de ayudas y subvenciones y demás programas de creación de empleo. De este modo, la OIT pretende evitar la configuración de programas de empleo que carezcan de una dimensión de género y asesora a los Ministerios nacionales competentes en la materia sobre la elaboración y aplicación de políticas nacionales de empleo. En este sentido, el propio Convenio OIT núm. 122, sobre política de empleo de 9 de julio de 1964, contempla un sistema que orienta a las legislaciones sobre la adopción de disposiciones normativas que eliminen la pobreza y fomenten el desarrollo de políticas de empleo orientadas a la no discriminación.

\section{EL PROBLEMA DE LA PRECARIEDAD EN EL TRABAJO: TRABAJO INFORMAL E INSEGURIDAD EN ELEMPLEO}

La precariedad laboral ha cobrado un protagonismo especial en el actual contexto de crisis económica y del empleo. Según Naciones Unidas, la pérdida del empleo por parte de las mujeres les ha obligado a buscar nuevas vías de ingresos recurriendo al empleo precario proveniente de la economía informal. Este nuevo espacio a la economía informal impide desde el punto de vista del género promover políticas eficaces para remover las situaciones injustas ${ }^{17} \mathrm{y}$, lo que es más grave, nuevos espacios sustraídos del ámbito de aplicación de las legislaciones laborales y de Seguridad Social. Ello supone ciertamente un obstáculo efectivo a la extensión de las políticas de igualdad de género y dificulta la interdicción de discriminación sexista. Anteriormente, comentamos que según la OIT la participación de la mujer en el trabajo ha ido aumentando, pero también existe un ámbito de presencia femenina en trabajos en los que no existe una remuneración digna, lo cual va en 
contra del objetivo del trabajo decente (pensemos, por ejemplo, en los trabajos agrícolas en África o Asia). De este modo, la OIT insta a los gobiernos nacionales a adoptar acciones concretas para proteger a las mujeres en el sector de la economía informal.

Una nueva manifestación de trabajo informal la encontramos en la presencia femenina en el trabajo por medio del autoempleo. El trabajo por cuenta propia femenino ha aumentado, siendo en la práctica una vía disuasoria de la protección laboral y social del trabajo por cuenta ajena, que implica un alto coste económico para la empresa ${ }^{18}$. Ciertamente, se trata de empleo formal desde el punto de vista normativo, pero en la práctica bajo esta figura se pueden ocultar trabajos propios de la economía informal, donde la remuneración es baja y las condiciones laborales se caracterizan por su contenido precario. Asimismo, los peligros de este tipo de trabajo afectan especialmente a la cobertura de los riesgos sociales, ya que en muchos países no se articulan mecanismos de tutela suficientes para el trabajo por cuenta propia.

El empleo precario representa múltiples problemas desde la perspectiva de género y afecta a las mujeres porque se muestran especialmente condicionadas a aceptar dichos empleos, que implican contratos devaluados y remuneraciones bajas. Estas circunstancias sitúan a este tipo de trabajo femenino en condiciones de subempleo presidido por el deterioro de las condiciones laborales. La OIT se ha referido especialmente a tres tipos de situaciones de precariedad que se proyectan con especial acción en el ámbito de la igualdad de género. Nos estamos refiriendo a los contratos temporales, el trabajo a tiempo parcial y el trabajo doméstico.

El trabajo temporal afecta especialmente a las mujeres debido a que generalmente los hombres ocupan puestos indefinidos que suponen el sostén económico de las familias, mientras que las mujeres compaginan en muchos casos la atención de las responsabilidades familiares con trabajos eventuales. La OIT ha destacado el considerable aumento de los empleos temporales y en muchos casos se producen fenómenos de temporalidad de carácter cíclico o, incluso, casos de relaciones temporales cuasipermanentes, que sitúan a la mujer en condiciones concretas de vulnerabilidad. Ello supone ocupar trabajos con contratos de corta duración, de duración temporal e incierta, o contratos temporales sometidos a sucesivas renovaciones que se conjugan con interrupciones contractuales. En definitiva, situaciones en muchos

18. La OIT considera que la participación de las mujeres en el empleo informal es desproporcionada y que si bien la proporción de hombres en el empleo por cuenta propia es más o menos similar a la de las mujeres, estas se centran más en los empleos por cuenta propia de peor calidad. 
casos injustificadas que suponen un abuso de derecho y que implican la imposibilidad de garantizar un trabajo decente a la mujer trabajadora. ${ }^{19}$

El trabajo a tiempo parcial ha ocupado un especial protagonismo en las acciones de las OIT. Ello se debe no solo a la lucha por condiciones dignas de trabajo, sino por la necesidad de atender a una modalidad de relación laboral que se ejerce generalmente por mujeres y que sirve de instrumento para articular la conciliación laboral y familiar ${ }^{20}$. El trabajo a tiempo parcial permite a las mujeres conciliar las tareas domésticas y las cargas familiares con el trabajo y, por otro lado, la empresa puede utilizar dicho contrato para ajustar sus recursos humanos con dosis de flexibilidad en virtud de la demanda del mercado laboral. Sin embargo, no cabe duda de los riesgos inherentes al trabajo a tiempo parcial, debido a que se trata de un recurso laboral que suscita opiniones contradictorias. Se presenta como una solución al desempleo femenino, aunque también se le achaca el ser un obstáculo en la carrera profesional de las mujeres. Igualmente, se trata de un tipo de relación laboral que puede generar condiciones futuras de pobreza llegado el momento de la jubilación.

Las acciones de la OIT se han dirigido a aumentar la disponibilidad de empleos a tiempo parcial en condiciones de equidad, velando por el respeto a la voluntariedad del trabajador de acogerse sobrevenidamente a esta modalidad de trabajo. ${ }^{21} \mathrm{Y}$ desde el punto de vista de la conciliación laboral y familiar, el trabajo a tiempo parcial tendría que presentarse como un recurso extensible a madres y padres que trabajan, permitiendo rebajar las desigualdades de género en el empleo. Debido a la conexión del trabajo a tiempo parcial con la conciliación familiar y laboral el recurso a esta modalidad contractual ha aumentado significativamente en los últimos diez años. Ello implica que en gran parte los aumentos de la participación de la mujer en el trabajo se deben a la aplicación del trabajo a tiempo parcial. Sin embargo, el problema reside una vez más en la calidad del empleo, ya que se trata en la práctica de trabajos poco cualificados, pertenecientes a categorías inferiores en la empresa que están generalmente peor

19. En el ámbito de la Unión Europea se han contemplado disposiciones normativas concretas que permiten atajar la inseguridad en el empleo temporal desde la aprobación de la Directiva 99/70/CE del Consejo, de 28 de junio de 1999, relativa al Acuerdo marco sobre el trabajo de duración determinada de la CES, la UNICE y el CEEP.

20. Por ejemplo, en EEUU o Japón el 70 por ciento del total de los trabajadores a tiempo parcial son mujeres.

21. Un modelo de referencia en materia de trabajo a tiempo parcial es Holanda, donde la legislación laboral ha conseguido extender dicha modalidad de trabajo consiguiendo una distribución considerablemente uniforme entre mujeres y hombres. Ello ha supuesto la normalización del trabajo a tiempo parcial, gracias a la aproximación en términos de tutela laboral entre el trabajo a tiempo completo y parcial. Esencialmente, este efecto se ha producido por el fomento de contratos a tiempo parcial de jornadas amplias, que lo aproximan al trabajo a tiempo completo. Precisamente, este es un problema esencial en la materia, ya que en determinados países, como Alemana o Reino Unido, las horas de trabajo a tiempo parcial son reducidas, cifrándose en promedio por debajo de las dieciséis horas semanales. 
remunerados ${ }^{22} \mathrm{y}$, por otro lado, el recurso al trabajo a tiempo parcial puede dar lugar posteriormente a dificultades efectivas para convertir la relación laboral en trabajo a tiempo completo.

Por su parte, el trabajo doméstico se muestra como un frente de lucha especial contra la discriminación múltiple, ya que junto al sexo en muchos casos la desigualdad radica en motivos étnicos o de extranjería. Este tipo de trabajo lo desarrollan generalmente mujeres (sobre todo mujeres jóvenes o mayores migrantes y sin estudios) y su demanda es muy elevada, especialmente, en países desarrollados. El trabajo doméstico es un una modalidad de trabajo precario debido a su conexión con el trabajo informal. ${ }^{23}$ Incluso se ha destacado la conexión del trabajo informal con el trabajo a domicilio con el calificativo de "trabajo invisible", ya que no se encuentra justamente valorado y no está protegido suficientemente en relación a la Seguridad Social. En este sentido, generalmente las legislaciones laborales de los Estados suelen contemplar un régimen jurídico especial y diferenciado para estos colectivos. Asimismo, dicha creciente demanda de este tipo de servicios se debe a la falta de respuesta por parte de los Estados a las necesidades de atención familiar, dada la carencia de servicios públicos adecuados de atención a familiar.

\section{DISPARIDAD EN LAS CONDICIONES DE TRABAJO ENTRE HOMBRES Y MUJERES: LA DESIGUALDAD EN LA OCUPACIÓN}

El papel de las mujeres trabajadoras víctimas de discriminación laboral no solamente se manifiesta en el momento de acceso al empleo, sino que también se refleja cuando ya están trabajando, dando lugar en muchos casos a situaciones de desventaja en comparación con los trabajadores ${ }^{24}$. Ello da lugar a diferencias salariales o, por ejemplo, en el cumplimiento de las jornadas máximas, al exigirse a las trabajadoras el desarrollo de jornadas largas de trabajo, así como otras manifestaciones, como sucede con la denegación de las bajas por maternidad. Igualmente, la situación afecta a la propia discriminación en la extinción del contrato de trabajo, lo cual implica por parte de los Estados la necesidad de seguir contemplando disposiciones jurídicas que protejan a las mujeres

22. En la Unión Europea, las condiciones esenciales de desarrollo del trabajo a tiempo parcial se han realizado en virtud de la Directiva 97/81/CE del Consejo, de 15 de diciembre de 1997, relativa al Acuerdo marco sobre el trabajo a tiempo parcial concluido por la UNICE, el CEEP y la CES

23. En este sentido destacamos el programa de la OIT sobre trabajadores a domicilio en la economía global en Asia Home workers in the Global Economy in Asia, cuya finalidad es conseguir fomentar condiciones dignas de trabajo. En el ámbito de latinoamérica destacamos el siguiente informe. Vid. TOMEI, M., Home work in selected Latin American countries: A comparative overview, OIT, Ginebra, 2000, pp. 38-39.

24. Vid. OIT: Igualdad en el empleo y la ocupación, Estudio General, 1988, capítulo I. 
trabajadoras de los despidos discriminatorios en relación al embarazo, estado civil o ejercicio de las responsabilidades familiares.

Ciertamente, las políticas de reducción de las diferencias de género han permitido aumentar las oportunidades de empleo de las mujeres y ello les facilita seguir avanzando en el cumplimiento de condiciones laborales análogas y el justo desarrollo de la promoción profesional. Por ello, se alerta que, a pesar del avance de las mujeres desde el punto de vista educativo y formativo, dicha circunstancia no tiene un fiel reflejo en el plano de las condiciones laborales. Ello supone que desde el punto de vista práctico se sigue observando una deficiente calidad del empleo femenino, lo que significa que en algunos países hay todavía un gran número de mujeres trabajadoras que no se encuentran protegidas por la legislación laboral en materias como la protección frente a los accidentes laborales, las enfermedades profesionales, las pensiones y el desempleo $^{25}$. Sin duda, el problema más importante reside en la segregación profesional, que no es más que un ejemplo de discriminación en la ocupación. Por ello, a pesar de superar progresivamente el difícil hándicap del acceso al empleo, las mujeres siguen encontrando aún obstáculos al ejercicio libre de la profesión deseada, debido a la existencia de modelos de segregación ocupacional. Ello supone que hombres y mujeres siguen trabajando en líneas generales en sectores específicos y ocupan puestos reservados a un determinado sexo.

Los problemas en la ocupación se muestran igualmente visibles en la segregación vertical, que implica que las mujeres no pueden acceder a puestos de decisión y control. En este sentido se ha indicado que a medida que se reduce la segregación horizontal aumenta exponencialmente la segregación vertical. Generalmente, son los hombres los que supervisan la actividad laboral en las empresas y toman las decisiones importantes en los procesos productivos ${ }^{26}$. Esta segregación vertical es un claro ejemplo de desigualdad, que implica la configuración del poder con base en criterios de sexo, lo cual tiene proyección en el desarrollo profesional de las cualificaciones y da lugar a la percepción de mayores ingresos económicos. Ciertamente, desde el punto social se produce un reparto de roles laborales, ya que la mujer solamente va a realizar trabajos peor remunerados y con un contenido laboral más pobre desde el punto de vista cualitativo. Así pues, junto al menor salario, las mujeres trabajadoras se ven relegadas a categorías

25. Vid. Organización de los Estados Americanos (Consejo Interamericano para el desarrollo integral), Líneas estratégicas para avanzar hacia la igualdad y no discriminación de género en el marco del trabajo decente, XV Conferencia Interamericana de Ministros de Trabajo, Puerto España, 2007.

26. Vid. BOURDIEU, P., La domination masculine, Le Seuil, Paris, 1998. 
profesiones inferiores y encuentran obstáculos a las posibilidades efectivas de promoción laboral.

Ciertamente, las mujeres han ido aumentando su presencia en los trabajos de alto nivel con contenido directivo, pero todavía existen diferencias evidentes y las mujeres encuentra dificultades de acceso a dichos puestos de dirección, tanto en el empleo privado como público. La OIT estima que todavía su presencia es muy baja y representa en torno al veintiocho por ciento en términos comparativos a la presencia masculina en dichos puestos de responsabilidad, siendo las diferencias más notables en países de Asia. El objetivo es la remoción de la desigualdad rompiendo el "techo de cristal", que se presenta como una barrera que dificulta a las mujeres el progreso a puestos de gestión y de dirección $^{27}$. A pesar de los avances realizados, aún hoy es muy difícil para las mujeres romper la barrera invisible del techo de $\operatorname{cristal}^{28}$. La OIT ha recomendado combatir la segregación vertical mediante acciones de discriminación positiva (vid. supra). Concretamente, desde el año 2007 se han creado varios programas de discriminación positiva dirigidos a los Estados, estableciendo sistemas de cupo o de reserva de empleo directivo a las mujeres trabajadoras. Por ejemplo, la Comisión Europea ha previsto que en los consejos de administración de las empresas deberá lograrse una representación de género equilibrada. Este sistema ha sido implementado por diversos Estados entre los que destaca Alemania, España o Noruega. En el caso alemán se han contemplado códigos societarios y cupos voluntarios en materia de igualdad de género. De mayor intensidad ha sido el cambio en el caso español, ya que las empresas antes de 2015 debían adoptar cupos que reserven a las mujeres entre el 40 y el 60 por ciento de los puestos en los consejos de administración. Esta sistema de cupos se aplica igualmente en Noruega, reservándose un mínimo del 40 por ciento de los puestos en los consejos de administración para ambos sexos. En la práctica la OIT cifra que la presencia femenina en los trabajos directivos ha aumentado de un siete por ciento en 2003 a un treinta y nueve por ciento en 2008.

A juicio de la OIT, otro de los problemas importantes que afecta a la ocupación se refiere al acoso sexual. Se trata evidentemente de un problema que afecta especialmente a la mujer trabajadora como

27. Vid. ANKER, R., "Women's access to occupations with authority, influence and Decision-Making Power", Departamento de Integración de Políticas, documento de trabajo núm. 44, Ginebra, OIT, 2005.

28. Las mujeres trabajadoras han aumentado su participación en las actividades administrativas y de gestión, pero la promoción se bloquea justamente en el momento de acceso a los puestos de dirección. Y en los casos en los que dicha promoción se produce ello tiene un escaso recorrido, ya que la actividad directiva queda relegada a los niveles de dirección más bajo. Vid. WIRTH, L., Breaking through the glass ceiling: women in management, OIT, Ginebra, 2001. UNIFEM, El progreso de las mujeres en el mundo 2000, Informe bienal de UNIFEM, Nueva York, 2000, p. 92. 
colectivo vulnerable. Ello se refiere, sobre todo, a mujeres jóvenes y dependientes económicamente. Igualmente, la vulnerabilidad está en clara sintonía con el carácter precario de los empleos, a mayor precariedad laboral mayor posibilidad de existencia de acoso en el trabajo $^{29}$. En este sentido, se han aplicado acciones concretas para introducir en las legislaciones laborales medidas para combatir el acoso sexual en los lugares de trabajo e intensificar la vigilancia del cumplimiento de las disposiciones legales. Pese a que la OIT se refiera expresamente en sus documentos al acoso sexual, no cabe duda de que la preocupación se extiende a otras manifestaciones de acoso como el verbal o físico $^{30}$. Evidentemente, la lucha contra el acoso está ligada con la garantía del bienestar en la empresa, lo cual fomenta un buen clima laboral e incide en el aumento de la productividad. ${ }^{3}$

\section{LA IGUALDAD DE RETRIBUCIÓN: LA DISMINUCIÓN DE LABRECHASALARIAL}

La supresión de la discriminación salarial entre hombres y mujeres es esencial para lograr la igualdad de género efectiva, el fomento de la equidad social y el trabajo decente ${ }^{32}$. Las diferencias salariales siguen teniendo una gran proyección en el trabajo femenino ${ }^{33}$, fenómeno que se explica debido a las actuales tendencias de precariedad en el empleo y segregación ocupacional. Incluso cuando se superan, por parte de las mujeres, los obstáculos en materia de acceso al empleo y promoción

29. Vid. HASPELS, N. - KASIM, Z.M. - THOMAS, C. - McCANN, D., Action against sexual harassment at work in Asia and the Pacific, OIT, Bangkok, 2001. REINHART, A., Sexual Harassment, addressing sexual harassment in the workplace. Amanagement information booklet, OIT, Ginebra, 1999.

30. Por ejemplo, la Directiva 2002/73 introduce en el artículo 2.2 de la Directiva 76/207, dedicado a delimitar el concepto de discriminación por razón de sexo, los conceptos de acoso y de "acoso sexual", en los siguientes términos: "acoso: la situación en que se produce un comportamiento no deseado relacionado con el sexo de una persona con el propósito o el efecto de atentar contra la dignidad de la persona y de crear un entorno intimidatorio, hostil, degradante, humillante u ofensivo. Acoso sexual: la situación en que se produce cualquier comportamiento verbal, no verbal o físico no deseado de índole sexual con el propósito o el efecto de atentar contra la dignidad de una persona, en particular cuando se crea un entorno intimidatorio, hostil, degradante, humillante u ofensivo".

31. En 1985, la Conferencia Internacional del Trabajo reconoció que el acoso sexual en el lugar de trabajo es perjudicial para el bienestar y la productividad de los trabajadores, así como para sus perspectivas de empleo y de promoción. En este sentido, en la Conferencia se pidió la inclusión de la lucha contra el acoso laboral en las políticas nacionales en beneficio de la igualdad de género.

32. Vid. OIT, Propuesta revisada de la Oficina para la medición del trabajo decente basada en las orientaciones recibidas en la Reunión tripartita de expertos sobre la medición del trabajo decente, Departamento de Integración de Políticas, Ginebra, 14 de octubre de 2009, p. 2.

33. En los últimos treinta años la disparidad salarial se ha ido reduciendo progresivamente en los países de la OCDE, aunque ciertamente se ha tratado de un proceso lento y complejo. Ejemplos de reducción de la brecha salarial se ha producido en países como Canadá, EE. UU, Francia o Suecia. Sin embargo, en los últimos años también se aprecia, por ejemplo en EE. UU y el Reino Unido un cambio de tendencia debido esencialmente a la crisis económica, que está repercutiendo en los logros de paridad salarial entre hombres y mujeres conseguidos y está generando nuevas situaciones de pobreza derivada de los salarios bajos y la precariedad laboral. Vid. OCDE: Perspectivas del empleo, París, 2002. En el ámbito de la Unión Europea, las diferencias salariales en términos de salario bruto entre hombres y mujeres se cifra en torno a un quince por ciento. Vid. Comisión Europea: Gender Equality Magazine: Equal Pay, núm. 11 (Luxemburgo, Publicaciones de la Comunidad Europea, 2001,p. 7. 
profesional mediante el reconocimiento de cualificaciones, se muestra la desigualdad de oportunidades en el plano salarial al ganar menos que los hombres por el mismo trabajo realizado. Esta circunstancia tiene su razón de ser en diversos factores como la segregación profesional, las estructuras de los salarios o, por ejemplo, los sistemas de clasificación profesional, cuyo margen de flexibilidad permite un tratamiento diferencial en la aplicación práctica de los sistemas salariales ${ }^{34}$. Igualmente, la desigualdad en las retribuciones se encuentra en otros motivos existentes en algunas legislaciones nacionales como, por ejemplo, en la restricción o prohibición a que las mujeres realicen horas extraordinarias o puedan trabajar en horario nocturno.

Sin duda, la declaración de la igualdad de remuneración por un trabajo de igual valor forma parte del principio fundamental de no discriminación en el empleo y en la ocupación. Precisamente, dicho principio se garantiza en la propia Constitución de la OIT de 1919, lo que significa que la OIT desde su propia fundación ha desarrollado dicho principio por medio de Convenios y Recomendaciones a los Estados. La OIT considera, pues, esencial garantizar la igualdad de la remuneración por un trabajo de igual valor, que es un derecho fundamental desarrollado en el Convenio núm. 100 de la OIT de 1951 sobre igualdad de remuneración, que obliga a los Estados miembros a "garantizar la aplicación a todos los trabajadores del principio de igualdad de remuneración entre la mano de obra masculina y la mano de obra femenina por un trabajo de igual valor" (art. 2.1) ${ }^{35}$. Posteriormente, dicho principio fue incorporado en la Convención de Nacionales Unidas sobre la eliminación de todas las formas de discriminación contra la mujer de 1979, que proscribe cualquier exclusión o restricción basada en el sexo de los derechos humanos y libertades fundamentales de las mujeres, y ello con base en el reconocimiento expreso de la igualdad del hombre y la mujer (art. 1) ${ }^{36}$.

El Convenio núm. 100 de la OIT ha sido ratificado por un gran número de Estados y en los últimos años se ha producido un aumento significativo de las ratificaciones realizadas por los Estados. Con todo,

\footnotetext{
34. Vid. OCDE, Gender Brief, OECD Social Policy Division, marzo de 2010, p. 13. CSI, Decisiones para trabajar: Análisis de los factores que influyen en las decisiones de las mujeres para trabajar, Bruselas, CSI, 2009 , pp. 28 y 29

35. Según datos de la OIT, el Convenio núm. 100 ha sido ratificado por 168 Estados miembros, siendo el quinto convenio más ratificado de la OIT y podemos hablar que tiene un nivel de ratificación del 90 por ciento, lo que significa que se aproxima al objetivo de la ratificación universal.

36. Asimismo, reflejo de estas acciones de la OIT es el reconocimiento en Europa de la paridad retributiva en virtud de la Directiva 75/117/CE del Consejo, de 10 de febrero de 1975, relativa a la aplicación del principio de igualdad de retribución entre los trabajadores masculinos y femeninos, posteriormente refundida por la Directiva 2006/54/CE del Parlamento Europeo y del Consejo, de 5 de julio de 2006, relativa a la aplicación del principio de igualdad de trato entre hombres y mujeres en el empleo y la ocupación.

246
} 
según la OIT, aún existen muchos países que carecen en sus legislaciones laborales de disposiciones que contemplen la igualdad de remuneración entre hombres y mujeres por un trabajo de igual valor. Según las observaciones derivadas de la Comisión de Expertos en la aplicación de los convenios y recomendaciones, aún se observa que la mayoría de los Estados no han contemplado en sus legislaciones nacionales el principio de igualdad de remuneración entre hombres y mujeres $^{37}$. Por tanto, es preciso que los gobiernos sigan avanzando en la reducción de la brecha salarial de género mediante iniciativas que atemperen la precariedad laboral y la segregación en el empleo. Ciertamente, el estímulo de las políticas de igualdad salarial se proyecta con mayor intensidad en países industrializados, donde la presencia del trabajo informal es inferior ${ }^{38}$. Según la Comisión Europea, las diferencias salariales entre hombres y mujeres tienen su razón de ser en el incumplimiento de la legislación sobre igualdad de remuneración, así como en las desigualdades de tipo estructural, esencialmente debido a la existencia de supuestos de segregación laboral ${ }^{39}$.

La OIT considera que la lucha contra la desigualdad salarial por motivos de sexo es una prioridad, máxime si tenemos en cuenta la situación real de las mujeres. Según los datos de la OIT, que se refieren a estudios realizados desde la perspectiva de la globalización económica, las mujeres perciben entre un setenta y un noventa por ciento menos de lo que ganan los hombres respecto de un trabajo de igual valor ${ }^{40}$. Dicha brecha salarial decrece sustancialmente en países desarrollados. Por ejemplo, en el ámbito de la Unión Europea se ha detectado que la discriminación directa o indirecta en las retribuciones da lugar a una brecha salarial de al menos el quince por ciento ${ }^{41}$. En este sentido, la OIT ha articulado distintos programas para que el principio de no discriminación en la remuneración permita el fomento del trabajo

37. Vid. OIT, Informe de la Comisión de Expertos en Aplicación de Convenios y Recomendaciones, Informe III (1A), 89. ․ㅜ reunión de la Conferencia Internacional del Trabajo, Ginebra, 2001, p. 21.

38. Vid. KIRKWOOD, E. - MALHOTRA, D., Economic opportunities for women in the East Asia and Pacific Region, Washington, D.C., Banco Mundial, 2010, p. 68.

39. Vid. Comisión Europea: Gender Equality Magazine: Equal Pay, núm. 11 (Luxemburgo, Publicaciones de la Comunidad Europea, 2001, p. 7.

40. Según la OIT, "según datos recientes, hay 829 millones de mujeres en el mundo que viven por debajo del umbral de pobreza frente a 522 millones de hombres. En una situación en que las mujeres perciben entre un 70 y un 90 por ciento de lo que ganan los hombres por un trabajo de igual valor, la no discriminación en la remuneración debería ser parte integral de las medidas a favor de la igualdad de género y la reducción de la pobreza". Vid. OIT, La igualdad en el trabajo: un objetivo que sigue pendiente de cumplirse, op. cit., p. 7. Más datos sobre la brecha salarial en términos internacionales se pueden consultar en el siguiente estudio. Vid. OIT: Informe mundial sobre salarios: Actualización 2009, Ginebra, 2009, párrafo 12. OIT: La igualdad de género como eje del trabajo decente, Informe VI, Conferencia Internacional del Trabajo, 98. ${ }^{a}$ reunión, Ginebra, 2009, párrafo 58.

41. Vid. BOULIN, J.Y. - LALLEMENT, M. - MICHON, F., "Decent working time in industrialized countries: Issues scopes and paradoxes", en Decent working Time: New Trends,new issues, Ginebra, OIT, 2006,pp. 32 
decente y ello genere políticas integrales y transversales a favor de la igualdad de género y la reducción de la pobreza. Y, asimismo, se considera esencial que los Estados realicen una labor de seguimiento del cumplimiento de las normas relativas a la igualdad de género.

Actualmente, los esfuerzos se centran en seguir proyectando el contenido del Convenio núm. 100 de la OIT en las legislaciones nacionales y fundamentalmente en la correcta recepción de la garantía de la igualdad en la remuneración por un trabajo de igual valor. Este principio tuitivo ${ }^{42} \mathrm{e}$ innovador supone que la comparación en términos salariales no se hace de forma genérica respecto de un trabajo análogo, sino que se pone énfasis en la referencia al contenido similar del propio trabajo. Las legislaciones nacionales aún se refieren en términos comparativos a un trabajo idéntico o similar, sin incluir la noción de trabajo de igual valor, que como estamos observando es un concepto mucho más tuitivo. Por tanto, el problema reside en la falta de comprensión de la diferencia entre los conceptos de igual remuneración por trabajos iguales o similares y de igual remuneración por trabajos de igual valor ${ }^{43}$. Ello puede dar lugar a supuestos de discriminación salarial que pueden ser directos, si se refiere a trabajos iguales o similares o, en su caso, indirectos, si la comparación se realiza con trabajos diferentes, pero de igual valor. Ciertamente, se trata de un problema de hondo calado, que produce profundas diferencias en relación a la ordenación salarial ${ }^{44}$.

Otro de los problemas en materia de igualdad salarial por motivos de género se refiere a la recepción del concepto de salario en las legislaciones laborales de los Estados. En este sentido, es preciso decir que el Convenio núm. 100 OIT se refiere a la igualdad salarial comprendiendo "el salario o sueldo ordinario, básico o mínimo, y cualquier otro emolumento en dinero o en especie, en concepto del empleo del trabajador" (art. 1). Por su parte, las leyes laborales nacionales no contemplan en muchas ocasiones conceptos de remuneración de carácter extensivo, que abarcan a todas las formas de retribución. En muchos casos, los Estados garantizan la igualdad retributiva solamente respecto del salario ordinario, es decir, sobre las retribuciones básicas del trabajador y no consideran otras

42. En Europa, el establecimiento del principio de igualdad de retribuciones se ha reconocido en todo su alcance, abarcando conforme a la reiterada doctrina del TJCE, no sólo los trabajos iguales sino también los trabajos de igual valor.

43. La OIT ha insistido en este sentido en combatir la discriminación directa e indirecta por motivos de género en la remuneración. Vid. OIT: La igualdad de género como eje del trabajo decente, Informe VI, Conferencia Internacional del Trabajo, 98. ${ }^{a}$ reunión, Ginebra, 2009, párrafo 294.

44. Vid. GUNDERSON, M., "Viewpoint: Male-female wage differentials: How can that be?", en Canadian Journal of Economics, vol. 39, núm. 1, 2006, p. 1-21. HARRIMAN, A. - HOLM, C., Steps to pay equity: An easy and quick method for the evaluation of work demands, Equal Opportunities Ombudsman, 2001. 
contraprestaciones económicas, lo cual provoca en la práctica supuestos de discriminación por motivos de sexo en lo que se refiere a los componentes flexibles del salario. Los problemas prácticos se encuentran en los sistemas de fijación del salario, que se basan en la productividad y no en la naturaleza del trabajo. Asimismo, existe una deficiente definición de los complementos salariales que premian la experiencia, el mérito o el rendimiento, que no se distribuyen equitativamente entre los trabajadores ${ }^{45}$. Con todo, es preciso indicar que la igualdad salarial en la remuneración entre hombre y mujeres no supone que ganen lo mismo en todo caso, ya que caben diferencias en el empleo siempre que estas sean justificadas. La finalidad es intentar por la vía de la igualdad de género dotar a las mujeres de condiciones salariales más equitativas $\mathrm{y}$, asimismo, subsanar la depreciación de los empleos femeninos, que tendrán que ser retribuidos en función de su valor real. En definitiva, la meta es que las mujeres trabajadoras sean retribuidas por su propio mérito y por su capacidad, teniendo en cuenta el resultado derivado del desarrollo del trabajo.

En este sentido, la OIT considera que una de las formas de combatir la diferencia salarial desde la perspectiva de género es la introducción de salarios mínimos en las legislaciones ${ }^{46}$, así como fomentar cláusulas salariales en la negociación colectiva que contemplen salarios mínimos en sectores y ocupaciones con mayor presencia femenina. Por ejemplo, en el Reino Unido desde la introducción en 1999 del salario mínimo se ha avanzado significativamente en términos de igualdad salarial. Efectivamente, una política de salarios mínimos podría contribuir a la reducción de las diferencias salariales, sobre todo, en los estratos inferiores de la estructura salarial, que son precisamente los ámbitos donde las mujeres trabajadoras sufren las prácticas discriminatorias por motivos de género.

Sin duda, la OIT ha insistido en que la evaluación de los puestos de trabajo es una de las formas más efectivas de detectar las desigualdades salariales, generalmente mediante auditorías salariales en los lugares de trabajo ${ }^{47}$. No cabe duda de la complejidad de la evaluación analítica de los puestos de

45. Vid. BLAU, F. - KAHN, L., "Wage structure and gender earnings differentials: An international comparison", en Economica, Oxford, Blackwell Publishers, Vol. 63, núm. 2503, 1996, pp. S29-S62. BRUEGEL, I. - PERRONS, D., "Deregulation and women's employment: The diverse experiences of women in Britain", en Feminist Economies, Londres, Routledge Journals, vol. 4, núm. 1, 1998, pp. 103-125.

46. OIT, La igualdad en el trabajo: un objetivo que sigue pendiente de cumplirse, op. cit., p. 26. OIT, La igualdad en el trabajo: afrontar los retos que se plantean, op. cit., p. 29. OIT, La hora de la igualdad en el trabajo, op. cit., p. 62 .

47. Ciertamente, esta labor de estudio convive junto a los trabajos relativos a otros indicadores de género como son las tasas de empleo y desempleo femenino, división del tiempo de trabajo y tiempo libre, carga de trabajo, la violencia contra las mujeres, etc. En este sentido, conviene indicar que la OCDE viene impulsando una base de datos de género que combina los indicadores existentes de desigualdad, que se refieren a la educación, salud, empleo o representación en la vida política. 
trabajo, que aún sigue siendo un desafío. No obstante, se han logrado grandes avances y los datos disponibles permiten tener una información que puede orientar las prácticas legislativas y administrativas de las instituciones especializadas en materia de género. La evolución de puestos de trabajo es esencial para comparar trabajos y salarios, y todo depende del contexto de referencia de análisis, ya que los datos no son uniformes. Por ejemplo, la disparidad salarial suele ser más reducida en el sector público que en el privado. Las evaluaciones de puestos son una fuente de información importantísima, que permite avanzar en la corrección de las diferencias salariales, dado que la igualdad salarial tiene distintas manifestaciones en función del contexto analizado. Por ejemplo, en Europa, el Parlamento Europeo recomendó a la Comisión Europea en 2008 el impulso del principio de igualdad salarial entre hombres y mujeres, mediante el desarrollo de acciones que pudieran evaluar y clasificar los puestos de trabajo por parte de los órganos especializados en igualdad de género ${ }^{48}$. Los métodos de evaluación de puestos de trabajo deben evaluar el impacto de la desigualdad salarial sin sesgo de género, como medio para combatir eficazmente la igualdad en las retribuciones. Ello implica comparar los puestos de trabajo teniendo en cuenta factores objetivos como las calificaciones y aptitudes, la responsabilidad y las condiciones de trabajo. En este sentido, debe darse preferencia al análisis del contenido del trabajo y no a las características ni al rendimiento de las personas que lo desempeñan. Esta es la técnica promovida por la OIT que pretende lograr una evaluación equitativa de los puestos de trabajo ${ }^{49}$.

Ciertamente, se debe superar la idea de que la mujer supone un coste superior para la empresa en comparación con el empleo de los hombres. Esta tesis plantea el empleo de la mujer como una carga debido a la consideración de las prestaciones por maternidad, el supuesto mayor absentismo femenino, la negativa a ampliar la jornada laboral y el menor grado de movilidad geográfica. Se trata, efectivamente, de una serie de prejuicios que contemplan al empleo de las mujeres como más oneroso que el de los hombres. Sin embargo, distintos estudios demuestran que dicho coste es muy bajo y representa casi el dos por ciento de las retribuciones de las mujeres trabajadoras y si se realiza un análisis comparativo teniendo en cuenta el coste no salarial (como la inversión

48. Específicamente, en el caso europeo, se manejan tres indicadores de género a efectos salariales. En primer lugar, destacan los indicadores para medir la discriminación, que ofrecen información sobre las desventajas y desigualdades. En segundo lugar, se estudian indicadores para medir los avances de las políticas contra la discriminación por razón de género, analizando el grado de aplicación de las disposiciones normativas contra la discriminación. Y, finalmente, se recurre a los indicadores para medir los efectos de las políticas y prácticas administrativas contra la discriminación, comprobando la efectividad y eficiencia de dichas acciones.

49. Vid. KATZ, C. - BAITSCH, C., L'égalité des salaires en pratique: Deux outils d' évaluation du travail non discriminatoire à l'égard des sexes, VDF y Georg Editeur, Ginebra, 1996, p. 27. 
en capacitación, indemnizaciones o el abono de salario por categorías profesionales), desde esta perspectiva, se puede apreciar que el sobrecoste de contratar a una mujer es prácticamente inexistente ${ }^{50}$. Igualmente, conviene destacar la importancia de los avances producidos en materia de seguridad social. En la mayoría de los países que han implementado una protección de la maternidad mediante prestaciones sociales públicas se impide que el coste de las prestaciones por maternidad tenga que ser soportado por las empresas, lo cual fomenta sin duda las condiciones de acceso al empleo de las mujeres trabajadoras.

\section{CONCILIACIÓN DE LAS RESPONSABILIDADES FAMILIARES Y LABORALES}

La masiva incorporación de la mujer al mercado de trabajo en un corto espacio de tiempo ha supuesto una verdadera convulsión en el reparto de los papeles atribuidos a los miembros de la familia, que ha exigido la adopción de medidas de conciliación de la vida personal, familiar y laboral. Ello repercute directamente en la mujer, que tradicionalmente se ocupa con un mayor protagonismo del cuidado familiar. Ello supone en la práctica la reducción de su libertad de trabajo, tanto en lo que se refiere a la libre elección entre trabajar o no, o bien en relación a la selección del tipo de trabajo en cuestión, ya que la dedicación intensiva a sus responsabilidades familiares les perjudica en el desarrollo de sus carreras profesionales.

La OIT está acometiendo acciones relativas a la búsqueda de un equilibrio efectivo entre hombres y mujeres en relación a la asunción de las responsabilidades del orden familiar y laboral. En el ámbito de Naciones Unidas, ya la Convención sobre la eliminación de todas las formas de discriminación contra la mujer, había declarado su preocupación por que las consecuencias negativas que una distribución desigual de las responsabilidades familiares entre mujeres y hombres repercute negativamente no sólo en la mujer sino también en el conjunto de la sociedad. Precisamente, dichas medidas laborales tienen que aplicarse sin sesgo de género, ya que al afectar a las familias no solamente tiene que contemplar como beneficiarios a las mujeres, sino también a los hombres ${ }^{51}$. Ello redunda, pues, en una idea integral y corresponsable de familia, que comprende a las responsabilidades de

50. Vid. ABRAMO, L - TODARO, R., Cuestionando un mito: costos laborales de hombres y mujeres en América Latina, OIT, Lima, 2002. GÁLVEZ, T, "Discriminación de género en el mercado laboral de América Latina: La brecha de ingresos 2001", capítulo III, en L. Abramo (Dir.), Trabajo decente y equidad de género en América Latina, OIT, Santiago, 2006, pp. 95-128.

51. Especialmente importante es la jurisprudencia europea en torno a la igualdad de género en las responsabilidades familiares, que representa un claro ejemplo de respuesta al necesario equilibrio entre el trabajo y la familia en Europa. Sin duda, la jurisprudencia europea está propiciando cambios hacia una posición neutra de las políticas de la Unión Europea sobre el equilibrio entre el trabajo y la vida personal. Vid. 
atención familiar (cuidado de hijos, dependientes y personas de edad avanzada) como una cuestión social que incide en el empleo y afecta irremediablemente al conjunto de la sociedad.

En el ámbito de la OIT es especialmente importante el seguimiento del Convenio OIT núm. 156, sobre trabajadores con responsabilidades familiares, de 23 de junio de 1981, así como la Recomendación núm. 165, que desarrolla el convenio de citado. Asimismo, igualmente podemos citar indirectamente como convenios de referencia el Convenio OIT núm. 111 sobre la discriminación en el empleo y la ocupación de 1958 y el Convenio OIT núm. 100 de 1951 sobre igualdad en la remuneración. Ciertamente, el Convenio núm. 156 es un claro ejemplo del desarrollo de la igualdad de género y el trabajo decente a otras esferas no estrictamente laborales, sino sociales, que repercuten inevitablemente en el trabajo por cuenta ajena. La preocupación de dichos textos normativos es impulsar políticas dirigidas a que los trabajadores con responsabilidades familiares, especialmente las mujeres trabajadoras, puedan ejercer su trabajo y puedan promocionar laboralmente sin verse sometidos a prácticas discriminatorias por razón de género. Sin duda, la medida laboral general que orienta la conciliación de la vida laboral y familiar es la aplicación de regímenes de trabajo más flexibles en relación al horario de trabajo y a los períodos de descanso laboral. Ello supone que dichas medidas van a recaer sobre las empresas, siendo sin duda estos costes laborales mejor atendidos generalmente por las grandes empresas $^{52}$ en comparación con las pequeñas y medianas empresas ${ }^{53}$.

En la Unión Europea se han adoptado acciones específicas en este ámbito. Concretamente, debemos destacar el llamado Plan de trabajo para la igualdad entre las mujeres y los hombres 2006-2010, que estableció como una de sus seis áreas prioritarias la conciliación de la vida privada y de la actividad profesional. Igualmente, debemos citar la Agenda de nuevas cualificaciones y empleos: una contribución europea hacia el pleno empleo, que atribuye carácter prioritario, en el marco de las políticas de impulso de la flexiseguridad, al "reciclaje profesional de las personas que retornan a la vida laboral después de un período de ausencia por cuidados de familiares dependientes".

52. La necesidad de aplicar medidas de conciliación e igualdad no ha sido cuestionada por las empresas. Sin embargo, su puesta en marcha no ha seguido el ritmo pretendido posiblemente por la constatación de una evidencia como es el hecho de que en la práctica sea el empresario el sujeto que tiene que soportar con la mayor parte de los costes laborales. Si los costes son elevados y la acomodación del funcionamiento de la empresa al ejercicio de los derechos de conciliación es difícil, nos encontraremos ciertamente ante una reticencia empresarial en su aplicación que afectará de modo directo al ejercicio mismo del derecho y, en general, al trabajo femenino, ya que en la actualidad son las mujeres las consideradas destinatarias principales de los beneficios que establecen las normas laborales de conciliación.

53. Vid. PEROTIN, V. - ROBINSON, A. - LOUNDES, J., Equal opportunities practices and performance in small and medium-sized enterprises: Preliminary findings, Ginebra, OIT, 2002. 
Sin duda, el tema central es la ordenación flexible y negociada del tiempo de trabajo en beneficio de las responsabilidades familiares y personales. Estas prácticas de gestión del tiempo de trabajo tienen beneficios para ambas partes del contrato de trabajo, debido a que junto al beneficio del trabajador de poder hacer frente a sus cargas personales compatibilizando el trabajo por cuenta ajena, la empresa igualmente tiene un interés en reducir el absentismo sobrevenido, la conservación del personal cualificado en el que ha invertido en materia de formación profesional y en la creación de un buen ambiente de trabajo que repercuta positivamente en la productividad ${ }^{54}$. Ello supone que siempre que la flexibilidad horaria sea posible y no afecte desproporcionalmente a la organización del trabajo, la empresa debería aceptar el traslado del tiempo no trabajado a días distintos, de forma fraccionada o íntegra. Estaríamos, pues, ante una modalidad de ausencias recuperables, que pudieran aplicarse de forma flexible para su adaptación a la empresa y a las características de cada supuesto. Ciertamente, estas medidas son difícilmente aplicables en sistemas rígidos de organización del trabajo, que se gestionan en virtud de objetivos, pero al margen de estos casos, las opciones para implementar la gestión flexible del tiempo de trabajo son muy variadas ${ }^{55}$.

Junto a la distribución flexible del tiempo de trabajo, cobra especial importancia la necesaria reducción de la jornada de trabajo en determinados momentos de la vida laboral de los trabajadores. Ello se muestra especialmente importante en una situación en la que las jornadas laborales son excesivamente largas, especialmente para las mujeres que se ocupan mayoritariamente del cuidado familiar ${ }^{56}$. De este modo, en momentos puntuales de carácter provisional la empresa tendría que permitir a sus empleados trabajar menos horas de las correspondientes a la jornada a tiempo completo y poder modificar sus horarios de trabajo en función de sus responsabilidades familiares ${ }^{57}$. En

54. Vid. MACDERMIND, S.M. - LITCHFIELD, L.C. - PITT-CATSOUPHES, M., "Organizational size and workfamiliy issues", en Annals of the American Academy of Political and Social Science, vol. 562, marzo de 1999, pp. 111-126.

55. Por ejemplo, adelantando o retrasando el horario de entrada y salida, siempre que se complete la jornada diaria efectiva establecida, o recuperando dentro del mes o el año las horas no trabajadas hasta completar lo previsto en el calendario laboral. Otro ejemplo de organización flexible es la denominada jornada intensiva, no solo en verano, sino también en períodos de vacaciones escolares como Navidad o Semana Santa. Asimismo, en los procesos organizados por turnos de trabajo rotativos se puede permitir cambiar voluntariamente de turno de trabajo garantizando que el servicio quede cubierto. Igualmente, se pueden fraccionar las vacaciones hasta en tres períodos o disfrutarlas en otros momentos que se adapten mejor al ejercicio de las responsabilidades familiares. Finalmente, conviene apuntar las posibilidades que ofrece el teletrabajo, en este caso flexibilidad no horaria sino espacial, que permite al trabajador que pueda continuar siendo miembro de la empresa desde cualquier lugar.

56. Precisamente, las amplias jornadas laborales dificultan la contratación de las mujeres en puestos de dirección, así como la estabilidad en el empleo y suponen ciertamente un claro elemento que incentiva la segregación ocupacional por motivos de sexo.

57. Vid. GRAY, M.C. - TUDBALL, J., "Family-friendly work practices: Difference within and between workplaces”, Australian Institute of Family Studies Research Report, núm. 7, Melbourne, 2002. 
este sentido, la medida prototípica en este punto es el trabajo a tiempo parcial, pero es preciso indicar que no siempre los trabajadores pueden recurrir fácilmente a este instrumento y posteriormente retornar a su originario puesto de trabajo sin problemas. Igualmente, sería necesario seguir dotando al trabajo a tiempo parcial de las condiciones necesarias para hacerlo atractivo y dignificar su aplicación práctica siguiendo, por ejemplo, la experiencia holandesa (vid supra) ${ }^{58}$.

Otro bloque de las políticas de la OIT en materia de conciliación de la vida laboral y familiar desde la óptica del género se refiere a las licencias parentales y a la protección de la maternidad y la lactancia. El instrumento normativo específico es el convenio OIT núm. 183 de 15 de junio de 2000, relativo a la protección de la maternidad, que garantiza el derecho de la mujer y su hijo al acceso a prestaciones que garanticen unas condiciones de salud dignas y un nivel de vida adecuado. El convenio ofrece una protección de la maternidad en conexión con la tutela de la salud de las madres, que solamente retornarán al trabajo cuando se recuperen fisiológicamente. Con todo, desde el punto de vista comparado, la OIT resalta que en relación a la protección de la maternidad todavía existen muchos países que no ofrecen una respuesta adecuada a la maternidad en aplicación de la normativa internacional ${ }^{59}$. $\mathrm{Y}$, sin duda, esta protección es esencial para asegurar la plena participación de las mujeres en el trabajo y, por tanto, se presenta como una piedra angular de la política de igualdad de oportunidades para las mujeres en el empleo. Sin duda, la finalidad es remover las situaciones de desigualdad por razón de género y evitar que la mujer trabajadora se encuentre estructuralmente desfavorecida en el empleo debido a la maternidad. De este modo, podríamos hablar de la existencia de ámbitos laborales excluidos para las trabajadoras debido a los problemas relativos a la conciliación del trabajo con la función reproductora y con la atención a la familia, generándose incluso situaciones de discriminación estructural.

Se trata ciertamente de un bloque sensible, ya que todavía son comunes las situaciones de discriminación relacionadas con el embarazo y la maternidad. En concreto, la mujer trabajadora se encuentra

58. En este sentido, se ha comprobado que la tasa de fecundidad crece en la medida en que se fomenta el acceso al trabajo a tiempo parcial y se facilitan servicios de guarderías infantiles en beneficio de los trabajadores con cargas familiares. Vid. HEIN, C., Reconciling work and family responsibilities: Practical ideas from global experience, Ginebra, OIT, 2005, pp. 10-11

59. Por ejemplo, en la Unión Europea el 78 por ciento de los países cumplen las normas de la OIT en relación a la protección de la maternidad. En África solamente el 39 por 100 de los países contemplan normas que garantizan prestaciones acordes con las normas internacionales. Por su parte, en Asia la cifra es aún más baja y sólo el 23 por 100 de los países contemplan en sus legislaciones reglas relativas a la protección de la maternidad. E, incluso, existen ejemplos significativos de ausencia de respuesta como EE. UU, que no proporciona ningún tipo de prestaciones sociales ligadas a la maternidad. 
especialmente afectada en la medida en que determinados puestos de trabajo no pueden ocuparlos debido a su función reproductiva y se producen supuestos conflictivos en relación al disfrute de las suspensiones del contrato previas y posteriores al parto ${ }^{60}$. Asimismo, se plantean controversias en la dinámica de la relación laboral, por ejemplo, debido a obstáculos en relación a los ascensos o a la imposibilidad de retornar a su puesto originario una vez disfrutado el período de maternidad. Incluso, aún persisten situaciones que parecen superadas como los supuestos de despidos relacionados con el embarazo y la lactancia ${ }^{61}$. Esta situación dista sobradamente de aquellos ámbitos empresariales que son receptivos a las necesidades derivadas de la maternidad, por ejemplo, concediendo semanas adicionales a la licencia de maternidad retribuidas, o la reducción de la jornada laboral en supuestos de enfermedad sin merma salarial.

La licencia por paternidad ha ido extendiéndose en las distintas legislaciones, animando a los padres a acogerse a estos períodos de suspensión del contrato de trabajo para atender al cuidado de sus hijos. Se trata de períodos relativamente cortos, que se disfrutan generalmente de forma posterior al nacimiento del hijo. En octubre de 2008, el Parlamento Europeo recomendó que los padres pudieran acceder a una licencia de paternidad equivalente a la licencia por maternidad, a excepción de su duración, aplicándose dicho derecho con independencia de la existencia de matrimonio. Este permiso puede ser voluntario, como ocurre en España y en Italia, donde el padre tiene derecho a disfrutar de trece días o dos semanas de licencia. Por ejemplo, en Portugal el período de licencia es de veinte días, siendo cinco de ellos de carácter obligatorio. En el caso de Finlandia, la duración de la licencia de paternidad es de veinticuatro días. Estas licencia por paternidad se financia generalmente por parte del empresario, por la Seguridad Social o por ambas vías de forma combinada en función de la legislación que analicemos. En la práctica, el acogimiento a este tipo de licencia está pensando en un contrato por tiempo indefinido y a jornada completa, lo cual supone que muchos padres no pueden disfrutarlo, especialmente aquellos que trabajan como autónomos o con contratos de duración determinada.

60. No olvidemos que la incapacidad temporal por enfermedad común aparece en la práctica como un subterfugio, objeto en muchas ocasiones de fraude, debido a la facilidad de la obtención de la baja médica y se presenta como una de las principales causas de absentismo. En este sentido, muchas situaciones transitorias relativas a problemas personales o familiares acaban amparándose en la incapacidad temporal, al no poder el trabajador recurrir a los tradicionales permisos y, por otro lado, se evita el recurso a la excedencia. Ello aconseja la introducción de días adicionales por asuntos propios no retribuidos, legitimando las ausencias del trabajo por motivos particulares siempre que concurra justa causa.

61. Vid. OIT, La maternidad en el trabajo. Examen de la legislación nacional. Resultados de la base de datos de la OIT sobre las leyes relacionadas a las condiciones de trabajo y de empleo, segunda edición, Ginebra, 2010,pp. 22-ss. 
Por su parte, las licencias para el cuidado de niños también han sufrido profundos cambios en los sistemas nacionales. Con carácter general, siguiendo las recomendaciones de la OIT, los países han venido articulando medidas para fomentar el recurso de los padres de familia a las licencias para el cuidado de hijos. Este incentivo al ejercicio de las licencias parentales por parte de los padres sigue siendo aún muy bajo y de escasa repercusión. En la Unión Europea la licencia parental se configura como un permiso individual de los trabajadores, hombres y mujeres. Es decir, se trata de un derecho que no pertenece únicamente a la mujer trabajadora por cuenta ajena (o funcionaria) que ha dado a luz, sino a ambos progenitores (Directiva 96/34/CE). La licencia parental se contempla como un período largo de ausencia del trabajo, que generalmente pueden acogerse a él tanto la madre como el padre y se reserva el empleo y puede que sea no remunerado. El ejercicio de este derecho por parte de los padres es aún muy reducido, en muchos casos influido por la reducción salarial o por la incidencia en la promoción profesional $^{66}$. Este efecto se predica, pues, tanto de la licencia parental como de los demás supuestos de suspensión del contrato de trabajo ligados a la maternidad y al cuidado familiar. Las madres siguen solicitando más este tipo de suspensiones, aunque se están apreciando progresivamente cambios esperanzadores en cuanto a un equilibrio en el ejercicio de dichos derechos.

Evidentemente, es necesario articular medidas dirigidas a la atención de niños y personas dependientes. Ello supone tener en cuenta determinados aspectos como la ampliación de los permisos laborales y los períodos de baja por maternidad y paternidad, las guarderías, así como la posibilidad de aplicar acciones positivas para reincorporar a los trabajadores al empleo una vez transcurrido los períodos de atención familiar. Se trata, en definitiva, de medidas de equilibrio profesional y personal ${ }^{63}$, que no sólo tienen una dimensión laboral, sino que igualmente repercuten en la protección social. En este sentido, se ha defendido el establecimiento de beneficios sociales adecuados para las mujeres y los hombres que cuidan a familiares mayores, enfermos o discapacitados, con el fin de considerar dichos períodos como coeficientes de corrección que compensen los efectos de la dedicación a la familia en los períodos de cotización necesarios para el acceso a las pensiones.

62. Vid. BOLLE, P., "La licencia para el cuidado de los hijos", en Perspectivas. Revista Internacional del Trabajo, vol. 116, Ginebra, OIT, 1997, pp. 119-139. BOLLE, P., "Parental leave" en M.F. Louthfi (Dir.), en Women, gender and work, op. cit., pp. 347-367.

63. Por ejemplo, los tiempos especiales para atender necesidades de distinta índole como el fallecimiento de hijos y cónyuge, traslado de domicilio, acompañamiento a consulta médica a familiares, ayuda al empleado para facilitar gestiones personales, etc. Vid. HEYMANN, J., Forgotten Families: Ending the growing crisis confronting children and working parents in the global economy, Nueva York, Oxford University Press, 2006, pp. 7-ss. 
No obstante, todo ello depende del tipo de sistema que estemos analizando, por ejemplo, en el Reino Unido y EE. UU el cuidado de los hijos se considera una responsabilidad individual. Se trata de un modelo que contempla compromisos meramente formales con la igualdad de género recogidos legalmente, pero no se articulan servicios públicos para su correcta atención. En cambio, en los países nórdicos se aplica el denominado modelo sustantivo-igualitario, donde se contemplan, junto a los compromisos formales, servicios públicos de apoyo en beneficio de la igualdad de género. Este modelo se está extendiendo por Europa occidental progresivamente, permitiendo la intervención del Estado en la atención familiar. De este modo se corrigen los problemas de equidad social, ya que las familias monoparentales y con bajos ingresos tienen problemas más importantes de acceso a los servicios de atención familiar.

En relación a la atención de los hijos a cargo, es esencial la existencia de servicios de guardería gratuitos o con precios razonables al que puedan acceder los trabajadores, aliviando así la carga del cuidado durante el horario de trabajo a otros miembros de la familia. Estos servicios de guardería permiten a mujeres y hombres poder participar plenamente en la vida laboral y poder desarrollar con normalidad sus carreras profesionales ${ }^{64}$. Y cuando estos servicios no existen, los trabajadores con cargas familiares se encuentra en un posición de desventaja. Incluso, esta situación ya ha sido tenida en cuenta por muchas empresas que han habilitado sus propios servicios de cuidado infantil a cargo de la empresa en beneficios de sus empleados ${ }^{65}$. En cualquier caso, debemos subrayar la necesidad del carácter gratuito o con precios razonables de dichos servicios, sobre todo, cuando se trata de trabajadores que perciben salarios bajos, que les impiden asumir el coste del cuidado de sus hijos. Sin duda, esta medida permitiría incrementar significativamente la participación de las mujeres en el trabajo. Igualmente, deberían implementarse servicios especiales análogos a los de guardería infantil dirigidos al cuidado de otros miembros dependientes de la familia, como mecanismo para conseguir la igualdad de género y solidaridad social.

\section{LA PROMOCIÓN EFECTIVA DE LA IGUALDAD DE GÉNERO EN CLAVE DE TRABAJO DECENTE}

El objetivo fundamental de la OIT es generar oportunidades para que, tanto hombres como mujeres, puedan acceder a un trabajo digno y productivo en

64. El Consejo Europeo de Barcelona de 2002 reclamó una política de incremento de las "estructuras de acogida", que incluye el concepto tradicional de guarderías y cifraba con guarismos bastante concretos, que no han cambiando significativamente, los efectos sociales de dichos servicios.

65. Ciertamente, estos servicios de guardería infantil estarían dirigidos a la atención de niños de corta edad, generalmente hasta los tres años. Se trata de atender a los niños que no se encuentran escolarizados o bien que a pesar de ir a la escuela necesitan de un refuerzo horario después de las clases para poder compatibilizar su horario educativo con el horario laboral de sus padres. 
condiciones de libertad, igualdad, seguridad y dignidad humana. Al igual que sucede en los demás ámbitos de proyección del trabajo decente, la actuación coordinada entre la OIT, organismos internacionales - especialmente en ámbito de Naciones Unidas- ${ }^{66}$, los gobiernos nacionales y los interlocutores sociales es un presupuesto general de la eficacia de las medidas de promoción de la igualdad de género. La OIT incorpora dentro de la noción de trabajo decente a la igualdad entre sexos como elemento primordial para que los cambios sociales e institucionales generen equidad y progreso económico ${ }^{67}$. El tratamiento de la igualdad de género en clave de trabajo decente tiene una relación directa con los cuatro objetivos estratégicos de la organización, es decir, promover los principios y derechos fundamentales en el trabajo, el crecimiento del empleo y la generación de oportunidades para los hombres y las mujeres, la mejora de la cobertura y la eficacia de la protección social y el fortalecimiento del diálogo social y el tripartismo (vid. infra). En definitiva, se insiste en la necesidad de avanzar en la prohibición de la discriminación como presupuesto esencial y necesario para suprimir las diferencias de género en las relaciones laborales ${ }^{68}$.

La OIT intenta promover la ratificación y aplicación de los convenios fundamentales sobre igualdad y no discriminación por razón de género $^{69}$. Se trata de medidas que tienen su origen en el propio seguimiento de la Declaración de la OIT relativa a los principios y derechos fundamentales en el trabajo, con el fin de detectar prácticas de discriminación y desigualdad en los lugares de trabajo a la hora de revisar las políticas nacionales dirigidas a remover dichos obstáculos ${ }^{70}$.

66. En este sentido, se ha resaltado que se debería intensificar la relación con otros organismos internacionales en el seno de Naciones Unidas, especialmente aquellos que trabajan especialmente en temas de igualdad y no discriminación. Por ejemplo, la Oficina del Alto Comisionado de las Naciones Unidas para los Derechos Humanos y la Entidad de Naciones Unidas para la Igualdad de Género y el Empoderamiento de las Mujeres. Vid. OIT, La igualdad en el trabajo: un objetivo que sigue pendiente de cumplirse, Conferencia Internacional del Trabajo, $100^{\mathrm{a}}$ reunión, Ginebra, 2011, p. 63. Igualmente, es sumamente importante la cooperación con los órganos regionales competentes como la Comisión Europea contra el Racismo y la Intolerancia, el Consejo de Europa y la Agencia de los Derechos Fundamentales de la Unión Europea.

67. Sobre las posibilidades de desarrollo de las políticas de género en el ámbito de Naciones Unidas. Vid. Junta de los Jefes Ejecutivos del Sistema de las Naciones Unidas para la Coordinación (JJE), United Nations system-wide policy on gender equality and the empowerment of women: focusing on results and impact, CEB /2006/2, 15 de diciembre de 2006: http://www.un.org/womenwatch/ianwge/gm/UN_system_wide P_S_CEB_Statement_2006.pdf

68. Téngase en cuenta la declaración de 2008 sobre el tratamiento justo del trabajo en un mundo globalizado. Vid. OIT, Declaración de la OIT sobre la justicia social para una globalización equitativa, adoptada por la Conferencia Internacional del Trabajo en su 97. a reunión, Ginebra, 10 de junio de 2008.

69. Por ejemplo, podemos destacar como hito importante la ratificación en 2005 por China el Convenio núm. 111 de 1958 relativo a la discriminación en el empleo y la ocupación, que ha dado lugar a la promulgación de leyes específicas sobre la promoción de la igualdad de género. Ciertamente, la ratificación por parte de China del Convenio núm. 111 en 2006 ha supuesto de facto la ampliación del ámbito subjetivo de aplicación de dicha norma, al aumentar exponencialmente el número de personas cubiertas por dicho instrumento normativo internacional. Con todo, y pesar del crecimiento del número de ratificaciones, todavía existen importantes Estados que no han ratificado el convenio núm. 100, por ejemplo, Estados Unidos o Japón.

70. En relación al desarrollo de las opciones de política legislativa en materia de igualdad de género recomendamos el siguiente trabajo de investigación. Vid. CABEZA PEREIRO, J., "Las políticas de conciliación al servicio de la igualdad entre hombres y mujeres", en AAVV, Conciliación de la vida familiary laboral y corresponsabilidad entre los sexos, Tirant lo Blanch, Valencia, 2011, especialmente, pp. 90-ss. 
En este sentido, tienen especial importancia los cuatro principales instrumentos jurídicos de la OIT, a saber, el convenio sobre la discriminación en el empleo y la ocupación de 1958 (núm. 111), el convenio sobre igualdad de remuneración de 1951 (núm. 100), el convenio sobre los trabajadores con responsabilidades familiares de 1981 (núm. 156) y el convenio sobre la protección de la maternidad de 2000 (núm. 183). Junto a los convenios internacionales, las actuaciones de la OIT tienen en cuenta las resoluciones adoptadas por la propia Conferencia Internacional del Trabajo, que es el órgano de máximo nivel en relación a las políticas de la OIT. En este sentido, destacamos la Resolución de junio de 2004 relativa a la igualdad entre hombres y mujeres, la igualdad de remuneración y la protección de la maternidad

La OIT ha venido diseñando planes generales de actuación dirigidos a la observancia de los principios y derechos fundamentales en el trabajo. Los planes de acción en materia de género se iniciaron a partir de noviembre de 1999. En ese momento, el Consejo de Administración de la OIT puso de relieve el carácter transversal de la perspectiva de género en la OIT, afectando a todos sus programas y actividades en el mundo del trabajo. El Plan de Acción para la Igualdad de Género y la Transversalización de la Perspectiva de Género se presentó al Consejo de Administración de la OIT en marzo de 2000, proporcionando un método participativo para integrar la igualdad de género en las políticas laborales. En este sentido, podemos destacar la importancia del plan de seguimiento relativo a la eliminación de la discriminación en el empleo y la ocupación para los años 2004 a 2007, que contemplaba como acciones prioritarias la supresión de las diferencias salariales por motivos de género ${ }^{71} \mathrm{y}$ el fomento de la igualdad racial y étnica teniendo presente la dimensión de género ${ }^{72}$. El último Plan de Acción sobre igualdad de género del Consejo de Administración de la OIT se aprobó en marzo de 2010 y continua en la senda del anterior plan del período 2008-2009. El plan fue de aplicación para el quinquenio 2010-2015, que impulsó el carácter transversal de las políticas de igualdad de género e incide en la necesidad de formular nuevas respuestas y políticas

\footnotetext{
71. Los trabajos de asistencia técnica en materia de cumplimiento de la igualdad de remuneración entre hombres y mujeres se impulsaron de forma especialmente importante a partir del año 2007. Vid. OIT, Informe de la Comisión de Cooperación Técnica, Consejo de Administración, 300. ${ }^{\mathrm{a}}$ reunión, Ginebra, noviembre de 2007, documento GB.300/TC/4

72. Se ha llamado la atención sobre la escasa importancia que se ha prestado a la discriminación de género concurrente con otros supuestos discriminatorios, lo que ya tuvimos oportunidad de comprobar al analizar la proyección de la discriminación por motivos múltiples. En relación a sus problemas desde el punto de vista de la cooperación y la asistencia técnica. Vid. OIT, Informe de la Comisión de la Igualdad de Género, Resolución relativa a la igualdad de género como eje del trabajo decente, Actas Provisionales núm. 13, Conferencia Internacional del Trabajo, 98. ${ }^{a}$ reunión, Ginebra, 2009. Desde el punto de vista europeo, destacamos el siguiente trabajo de investigación. Vid. FREDMAN, S., "Positive rights and duties: Addressing intersectionality", en D. Schiek y V. Chege (directores): European Union non-discrimination law: Comparative perspectives on multidimensional equality law, Londres, Routledge-Cavendish, 2008, p. 84.
} 
favorables a la igualdad de género, teniendo en cuenta el impacto de la crisis en la situación de las mujeres y de los hombres e integrar las consideraciones relativas al género en todas las medidas gubernamentales $^{73}$.

La Oficina de Igualdad de Género se encarga de incorporar las cuestiones de género en los planes de acción de la $\mathrm{OIT}^{74}$, medidas que se han venido reforzando desde el año 1999. Ciertamente, se trata de un organismo central en las políticas de igualdad de género, que forma parte de la propia Secretaría de la OIT y fomenta la perspectiva de la igualdad de género, asesorando en el propio seno de la OIT. Asimismo, dicha oficina se coordina con el Consejo de Administración de la OIT y rinde cuentas al Director General con vistas a conseguir la eficaz implementación de la igualdad entre sexos en el trabajo. Sin duda, su labor más importante es la coordinación de los planes de acción de la OIT, en los que se incluyen las auditorías de género, y elabora las directrices generales de la política de género en la OIT. Igualmente, selecciona los proyectos de cooperación técnica en los que está presente la vertiente de género y colabora en los procesos de diálogo intergubernamental.

La Oficina de Igualdad de Género coordina la Red sobre Género de la OIT, que está constituida por un equipo internacional de especialistas en cuestiones de género. Básicamente uno o dos especialistas por región y por un conjunto de coordinadores (más de cien) que favorecen la proyección de la perspectiva de género en las unidades de la Organización. La Red de Género de la OIT se presenta como un foro de encuentro de los especialistas, que analizan la proyección práctica de los problemas laborales relativos a la igualdad entre hombres y mujeres. Concretamente, presta asistencia técnica y facilita el intercambio de experiencias y prácticas nacionales. Igualmente, analiza de forma permanente los costes y los beneficios de la promoción de la igualdad de género, así como las tendencias y las causas subyacentes en la diferencia de trato. Por su parte, el Fondo Asociativo para la Igualdad de Género, constituido en el año 2003, ha promocionado dichos proyectos aumentado progresivamente el número de Estados involucrados en los programas de acción. Igualmente, su labor se enmarca en la asistencia y cooperación técnica y ha incorporado la perspectiva de género de los programas de trabajo decente por países.

73. Vid. OIT, Plan de acción de la OIT sobre igualdad de género 2010-2015. Fase I: Armonizada con el Programa y Presupuesto para el bienio 2010-2011, Oficina Internacional del Trabajo, Ginebra, 2010.

74. Sobre la organización y funciones de la Oficina para la Igualdad de Género puede consultarse la website institucional. Vid. http://www.ilo.org/gender/lang--en/index.htm 
El mecanismo principal de la OIT para impulsar la igualdad de género se ha instrumentalizado por medio de los programas de trabajo decente por países, que han incluido la igualdad como objetivo esencial para el logro de condiciones laborales dignas. Actualmente, los programas de la OIT sobre trabajo decente e igualdad de género han reforzado progresivamente en los últimos años la inclusión de la perspectiva de género, prestando especial atención al grado de ejecución de los objetivos propuestos. Uno de los objetivos esenciales de los programas es el desarrollo e intercambio de conocimientos y experiencias en relación a la eliminación de la discriminación en el empleo y la ocupación. Dichos programas se configuran igualmente como planes de acción dirigidos a armonizar las legislaciones nacionales a los convenios de la OIT, salvando los problemas existentes relativos a la aplicación del principio de no discriminación en el trabajo. Sin duda, en este contexto cobra especial importancia la vigilancia de la OIT del nivel de seguimiento de los convenios internacionales, especialmente por medio de los órganos de seguimiento de los tratados internacionales, así como por los propios mecanismos especiales existentes en Naciones Unidas sobre la observancia de las prácticas nacionales derivadas de los tratados internacionales.

El seguimiento de la aplicación de los Convenios Internacionales se realiza por la Comisión de Expertos en la Aplicación de Convenios y Recomendaciones, labor especialmente intensa en estas dos últimas décadas. Se trata de auditorías desde la perspectiva de género por parte de las unidades exteriores de la OIT, que comenzaron a aplicarse desde el año 2001, y se muestran como una medida innovadora en el propio seguimiento de los convenios internacionales en el seno de Naciones Unidas. Las auditorías de género permiten evaluar y mejorar el conocimiento de los problemas ligados a la igualdad de género. Concretamente, la propia OIT evalúa los avances en materia de género con base en tres indicadores esenciales. En primer lugar, se tiene en cuenta el nivel de ratificación de los convenios internacionales y el grado de aplicación por parte de los Estados de los cuatro convenios centrales en la materia. En segundo lugar, se consideran las reformas legislativas realizadas y las políticas de género impulsadas por las Administraciones especializadas y, por último, el grado de participación de la mujer tanto en las acciones impulsadas por la OIT, así como en los propios órganos de gobierno de la misma.

Los proyectos de asistencia técnica tienen su proyección en países de Asia, África, América Latina y Europa, siendo cinco de ellos específicos en materias de género, aunque con carácter general la vertiente de género está presente en cada uno de ellos. Los programas se proyectan 
sobre un total de treinta y seis países y tienen como principal foco de atención la igualdad salarial y la eliminación de supuestos discriminatorios en el acceso y la dinámica de la relación laboral. Y, posteriormente, se ha venido incorporando a los objetivos la promoción de la maternidad y el equilibrio entre el trabajo y las responsabilidades familiares de los trabajadores ${ }^{75}$. El programa transnacional de mayor ámbito de aplicación es el denominado BASIC (Brasil, Angola, Sudáfrica, India y China). Se trata de un programa de acción específico sobre igualdad de género ${ }^{76}$, que promueve la adopción de medidas relativas a la aplicación de la igualdad, formación de género y organización de auditorías que proporcionan datos estadísticos de las condiciones laborales desglosados y teniendo en cuenta la variable sexo y el impacto de la economía informal en dichos sistemas productivos.

Los programas pretenden, pues, avanzar en la aplicación efectiva del derecho fundamental a la no discriminación, fortaleciendo la unión de los países y promover dicha alianza internacional respecto de países cuyas legislaciones aún no contemplan la vertiente de género como uno de los principios inspiradores de sus legislaciones nacionales ${ }^{77}$. Ciertamente, se trata de programas que fomentan la igualdad de género desde el punto de vista de la cooperación al desarrollo ${ }^{78}$. Por ello, la asistencia técnica en la adaptación de las legislaciones y prácticas nacionales a los convenios internacionales se muestra como un aspecto esencial desde el punto de vista de la coordinación de las normas internacionales del trabajo con las legislación nacionales. En este sentido, los Informes globales de la OIT indican, por ejemplo, que aún la igualdad de remuneración entre hombres y mujeres por un trabajo de igual valor sigue siendo un concepto que ofrece problemas prácticos de interpretación y aplicación. Ciertamente, esté es un aspecto central para la lucha contra la discriminación, ya que la interpretación de los Estados de dicho principio suele abordarse de forma limitada en las disposiciones legales y reglamentarias. Igualmente, cobra especial importancia la incorporación de las consideraciones de género a las políticas de empleo, que supone reducir el grado de desigualdad mediante la adopción de medidas en clave de igualdad de oportunidades en el acceso, promoción

\footnotetext{
75. En relación a la conciliación familiar destacamos la publicación oficial de la OIT. Vid. HEIN, C CASSIRER, N., Soluciones para el cuidado infantil en el lugar de trabajo, Ginebra, OIT, 2010.

76. Igualmente, dentro de las acciones de la OIT en materia de igualdad de género ocupa especial protagonismo la formación especializada de los profesionales de los Estados encargados de temas de género. En concreto, el Centro Internacional de Formación de la OIT, con sede en Turín, contempla acciones formativas especiales para jueces, inspectores, abogados, profesores e investigadores

77. Un hito importante en esta materia fue sin duda la promoción del programa relativo al Decenio del Trabajo Decente en Asia y la Década de la Promoción del Trabajo Decente en las Américas en el año 2006.

78. En este sentido, se ha propuesto como objetivo futuro la promoción por parte de la OIT de los programas de trabajo decente por países en el marco de la asistencia de Naciones Unidad para el Desarrollo (UNDAF). Vid. OIT, La igualdad en el trabajo: un objetivo que sigue pendiente de cumplirse, op. cit., p. 63.
} 
en el empleo y formación profesional. No cabe duda de que el resultado final de las medidas depende del grado de implicación y de la ejecución de los compromisos asumidos por los Estados, que se tienen que reflejar finalmente en leyes y políticas antidiscriminatorias.

En este sentido, la OIT ha puesto como ejemplo la labor realizada en los países miembros de la Unión Europea y considera como un referente los avances experimentados debido a la proliferación de las leyes de igualdad. Estas leyes nacionales se han promulgado por los Estados al transponer la Directiva núm. 2000/78/CE del Consejo Europeo, relativa al establecimiento de un marco general para la igualdad de trato en el empleo y la ocupación. Ello ha desencadenado un proceso de promoción de medidas antidiscriminatorias, reglas de la paridad en el trabajo e, incluso, un refuerzo institucional del seguimiento de las políticas de igualdad de género. En este sentido, podemos destacar sobre todo en el contexto europeo la creación de oficinas del defensor del pueblo dedicadas a temas de discriminación. En concreto, el Defensor de Igualdad de Oportunidades [por ejemplo en Suecia el Diskrimineringsombudsmannen (2001)] o en otros supuestos mediante la creación de Comisiones de Derechos Humanos, como sucede en el caso del Reino Unido o Brasil. Con todo, aún es preciso avanzar en la protección integral de la discriminación, teniendo especialmente en consideración los problemas derivados de las discriminaciones múltiples (vid supra). En el ámbito europeo, ello supone reforzar la conexión inevitable entre la Directiva 2000/78/CE con la Directiva 2000/43/CE del Consejo, de 29 de junio de 2000, relativa a la aplicación del principio de igualdad de trato de las personas independientemente de su origen racial o étnico. Ello implica adoptar políticas integrales de lucha contra la discriminación en el lugar de trabajo. En este sentido, ya en la Estrategia Europea de Empleo (EEE) se destacó la importancia de integrar las consideraciones de género y la promoción de la igualdad entre hombres y mujeres como un aspecto esencial en la consecución de condiciones laborales dignas ${ }^{79}$.

79. En el ámbito de la Unión Europea, desde al año 1997 la Estrategia Europea de Empleo ha impulsado la promoción de la igualdad de género en las políticas activas de empleo, que pueden adoptarse en diferentes ámbitos, siendo ello una consecuencia más de su naturaleza transversal. La proyección de la igualdad de género en las políticas de empleo afecta, pues, a aspectos tales como los servicios de búsqueda de empleo, contratación y colocación, programas de formación, subvenciones y ayudas a la contratación y al autoempleo, programas de creación de empleo y servicios específicos de asistencia y apoyo. En este sentido, podemos destacar la recomendación por parte de la OIT de la creación de programas de promoción de la autonomía de las mujeres por medio de planes de microfinanciación, que promueven la autonomía de las mujeres y abren vías de acceso al autoempleo. Vid. OIT, La igualdad en el trabajo: un objetivo que sigue pendiente de cumplirse, op. cit., p. 37. OIT, La hora de la igualdad en el trabajo, loc. cit., pp. 94-ss. Se trata, pues, de promover acciones para garantizar la presencia femenina en el mercado de trabajo. Según los compromisos alcanzados, los Estados miembros tienen que formular anualmente en sus planes nacionales de acción sobre el empleo medidas relativas a la igualdad de género. En este sentido, conviene recordar que la EEE se marcó para el año 2010 la consecución de unas tasas de empleo femenino del sesenta por ciento (Cumbre de Lisboa de 2000). 
Sin duda, entre las medidas de política legislativa promovidas por la OIT destaca el objetivo de conseguir medios de tutela eficaces para luchar contra la discriminación. Precisamente, el problema de la falta de coercibilidad de las normas internacionales hace necesario reforzar desde el punto de vista nacional la protección de los colectivos más vulnerables. En este tema tiene especial importancia el papel a desempeñar por los tribunales y la administración laboral, que se manifiestan como instrumentos que garantizan el cumplimiento efectivo de la legislación social. En este sentido, se insiste en reforzar el papel de la Inspección de Trabajo, que en su labor sancionadora puede prevenir las prácticas discriminatorias frente a la empresa. Igualmente, se debería intensificar su grado de intervención en los procesos laborales, permitiendo tanto la formulación de demandas, así como la actuación a propósito de las acciones judiciales incoadas previamente por las partes.

Por lo que se refiere a la faceta jurisdiccional, la OIT insiste en la necesidad de adaptar los procedimientos para que se protejan los derechos y se garanticen las condiciones para la adecuada reparación de los daños y perjuicios derivados de las prácticas discriminatorias. Especialmente, tendrían que asegurarse cauces procesales que permitan el desarrollo de la tutela judicial efectiva. Ello supone la necesidad de asegurar una asistencia jurídica accesible y que la justicia sea un recurso factible especialmente para las trabajadoras víctimas de discriminación, sin que se fomente la renuncia a las reclamaciones judiciales debido a su elevado coste o por el temor a sufrir futuras represalias laborales, lo cual vulnera el principio de indemnidad laboral. Igualmente, la OIT insiste en la necesidad de poder invocar en los procesos laborales la aplicación de las normas internacionales de trabajo, debido a que éstas sean reconocidas por los Estados como fuentes del Derecho. Asimismo, se insiste en la conveniencia de recurrir a los medios de resolución extrajudicial como la mediación y el arbitraje, así como adoptar medidas de prevención de las prácticas discriminatorias evitando los conflictos judiciales.

\section{DIÁlOGO SOCIAL Y NEGOCIACIÓN COLECTIVA: CAUCE CLAVE PARA LA REDUCCIÓN DE LAS DIFERENCIAS EN LAS CONDICIONES LABORALES}

Sin duda, la promoción de condiciones de igualdad en el trabajo es una responsabilidad primordial de los Estados, cuyas políticas legislativas y prácticas administrativas tienen que estar orientadas a este objetivo. Sin embargo, el papel de los agentes sociales por la vía del diálogo social y el 
entendimiento de los sujetos de las relaciones laborales por medio de la negociación colectiva es decisivo a los efectos de garantizar la aplicación efectiva del principio de igualdad. La OIT ha venido apostando tradicionalmente por el diálogo social como instrumento clave para conseguir la paridad en el trabajo, potenciando la defensa de la igualdad con los agentes sociales desde un punto vista internacional. Este diálogo se mantiene de forma estable con organizaciones empresariales y sindicales internacionales, esto es, con la Organización Internacional de Empleadores (OIE) y con la Conferencia Sindical Internacional(CSI). Ello ha permitido incorporar las consideraciones de género al diálogo social como un aspecto de naturaleza transversal, que tiene proyección en las condiciones de trabajo y empleo, creando redes y cauces de cooperación con las federaciones patronales y sindicales internacionales ${ }^{80}$. Precisamente, la propia OIT gradúa el grado de desarrollo económico y social de un país por el nivel de diálogo social y por el índice de cláusulas de igualdad de género presentes en la negociación colectiva.

Se trata de un elemento esencial ya que los interlocutores sociales están llamados a desplegar un papel protagonista en la reducción de las diferencias en las condiciones laborales, especialmente, las salariales por medio del juego del diálogo social. Y, sin duda, dicho diálogo social en clave de género tiene que proyectarse necesariamente en el ámbito nacional ${ }^{81}$, teniendo en cuenta las concretas particularidades de los mercados de trabajo respecto al trabajo femenino. Indudablemente, en este sentido tiene especial importancia el fortalecimiento de las instituciones para el diálogo social, como consecuencia directa de la participación de los agentes sociales en las políticas sociales y como un claro ejemplo de fortalecimiento de la democracia social. De este modo, los principales actores pueden influir y concertar socialmente cambios que permitan reformas sociales que incluyan cuestiones relativas a la garantía de la igualdad de género. Dicha influencia de los interlocutores sociales puede repercutir en la promoción de la igualdad en el trabajo, creando contextos de desarrollo digno de las condiciones de trabajo.

80. En este sentido, conviene recordar los esfuerzos realizados en las campañas de sensibilización "Trabajo decente, Vida Decente" de la CSI, cuyos objetivos esenciales son promover el trabajo decente para la mujer y la igualdad de género en las políticas y los convenios laborales y aspirar a la igualdad de género en las estructuras, políticas y actividades sindicales con un significativo incremento en el número de mujeres afiliadas a los sindicatos y su presencia en los cargos de responsabilidad. En este sentido, tanto la CSI, así como las Federaciones Sindicales Internacionales (FSI) se han venido centrando en los sectores y áreas de trabajo donde las trabajadoras resultan más vulnerables, como son las zonas francas industriales, el trabajo doméstico, el trabajo a tiempo parcial, el fenómeno de la migración y la economía informal.

81. Por su parte, igualmente, podemos destacar las campañas de la OIE relativas a la promoción del trabajo decente desde la perspectiva empresarial, en las que se insiste en que no existe un modelo único del trabajo decente. Ello supone que si bien es cierto que el trabajo decente no tiene "techo", se subraya la idea de que se trata de un objetivo que debe contemplarse en el marco de cada contexto nacional y en función de sus realidades económicas y sociales. Vid. OIE, Trabajo decente. Como llevarlo a la práctica: el punto de vista de los empresarios, Ginebra, 2002. 
Sin duda, la negociación colectiva es un instrumento central y se convierte en un medio para conseguir mejoras en pro de la igualdad de género. Ciertamente, es preciso avanzar en la negociación colectiva de la igualdad de género debido a la ausencia en muchos casos de cláusulas de igualdad o cuando existen debido a su carácter limitado. De este modo, los convenios colectivos pueden incluir cláusulas antidiscriminatorias a favor de la igualdad, siendo este un aspecto que no se debe analizar de forma atomizada, sino que tiene que ser un principio transversal que condicione el conjunto de las condiciones de trabajo y empleo previstas en los convenios colectivos. Y, en este sentido, los convenios colectivos como fuente del Derecho tienen que realizar conexiones necesarias con la legislación laboral de contenido antidiscriminatorio, mejorando y especificando sus efectos en el ámbito concreto de aplicación del convenio colectivo ${ }^{82}$. Por tanto, la negociación colectiva está llamada a integrar, desarrollar o completar buena parte de los derechos de conciliación que el ordenamiento jurídico reconoce y que sin duda el tratamiento realizado ha sido escaso y relativo a aspectos muy puntuales, muy lejos de la vocación transversal que ocupa a la igualdad de género.

Todo ello requiere reforzar dicha transversalidad y no limitar su tratamiento en los convenios colectivos a las cláusulas relativas a la protección de los derechos ligados a la maternidad, que es el contenido típico y tradicional, pero que no satisface las necesidades de tutela de la igualdad de trato y no discriminación por razón de sexo. Por tanto, el cambio en las dinámicas negociadoras tiene que afectar a aspectos como las acciones positivas, el horario flexible, la igualdad de remuneración, el permiso parental, el acoso sexual, etc. Especialmente importante es la reconfiguración de los sistemas de clasificación y promoción profesional, que tienen que tener una configuración neutral en clave de género. Ello implica correlativamente una valoración de los puestos de trabajo de forma objetiva que permita erradicar las desigualdades de remuneración, incluyendo las cláusulas de igualdad de remuneración en los convenios colectivos ${ }^{83}$. Asimismo, se insiste en la necesidad de introducir en la negociación colectiva el recurso a técnicas de

82. En este sentido, podemos destacar los propios esfuerzos realizados por la OIT, con la Guía práctica para la incorporación sistemática del empleo y el trabajo decente. Aplicación a nivel de país, Ginebra, 2008, pp. 25-ss. Debido al carácter transversal de la perspectiva de género, el tratamiento de la igualdad entre hombres y mujeres está presente en todo el documento.

83. En este sentido, podemos destacar el camino iniciado en Francia por la Ley núm. 2001-397, de igualdad de oportunidades de empleo, que obliga a las empresas a promover la igualdad de oportunidades para hombres y mujeres por medio de la negociación colectiva, lo cual ha supuesto una avance significativo de la mujer en puestos de trabajo donde tradicionalmente han estado insuficientemente representadas. Los convenios colectivos han fomentado la paridad en el acceso al empleo por medio de los denominados contracts pour la mixité des emplois. 
organización de la actividad laboral, como el teletrabajo, el trabajo ${ }^{84}$ compartido y el trabajo flexible, que ha tenido especial proyección en la negociación colectiva de los países europeos, aunque es preciso vigilar la aplicación de dichas prácticas ya que pueden generar indirectamente relaciones de empleo precarias. Asimismo, podemos destacar las posibilidades que tiene la negociación colectiva de contemplar cauces de resolución extrajudicial de conflictos laborales, más rápidos y menos costosos que los procesos judiciales, lo cual puede suponer una vía de refuerzo de la tutela de la igualdad.

Sin duda, es indudable que los ámbitos sectorial y supraempresarial son los contextos idóneos del desarrollo de los acuerdos. La negociación colectiva descentralizada representa un elemento de debilidad, que impide remover las condiciones que determinan las desigualdad en el empleo entre hombres y mujeres, muy especialmente las salariales. Con todo, debemos destacar que es necesario avanzar en la coordinación de la negociación sectorial y empresarial para evitar la citada descentralización de la negociación colectiva que fomenta condiciones dispares, como sucede por ejemplo con las diferencias salariales. El avance en la negociación colectiva de la igualdad de género implica, pues, un cambio cualitativo de las tendencias negociadoras, así como en el propio contenido objetivo de los acuerdos colectivos. Ello supone avanzar decididamente hacía un nuevo modelo de negociación, que supere y complete las reivindicaciones de los trabajadores con la seguridad en el empleo y la defensa del nivel salarial frente a la demanda empresarial de mayores márgenes de flexibilidad en la organización del trabajo. En realidad, la negociación de la igualdad de género se presenta como un presupuesto necesario, que condiciona el conjunto de condiciones laborales, actuando como máxima directamente relacionada con la equidad y la propia dignidad de los trabajadores. No obstante, el objetivo es sumamente difícil de lograr, dado el carácter antagónico de los intereses que concurren de forma indudablemente conflictiva. Por un lado, el interés empresarial de conquistar parcelas de autoorganización del trabajo en beneficio de la productividad y, de otro, el interés de los trabajadores de mantener y, en su caso, mejorar los derechos laborales bajo la perspectiva de la equidad y la redistribución social entre hombres y mujeres, incluyendo medidas de acción positiva en el trabajo.

84. Sobre la supresión de las prácticas discriminatorias en relación a la remuneración. Vid. DICKENS, L., Equal opportunities and collective bargaining in Europe.4. Illuminating the process (Luxemburgo, Oficina de Publicaciones Oficiales de las Comunidades Europeas, 1998. JOLIDON, G., La lutte contre la discrimination dans l'emploi et la profession par le biais des conventions collectives de travail, documento preparado para el Programa InFocus sobre la Promoción de la Declaración, Ginebra, OIT, 2001. PILLINGER, J., Equité salariale, maintenant! Dossier d'information sur l'équité Salariale, ISP, Bruselas, 2002. 
Se trata, sin duda, de un sistema de negociación que tiene una mayor tradición en los países industrializados, que generalmente incluyen pactos de igualdad salarial en los convenios colectivos. En cambio, en los países en vías de desarrollo éstas son cuestiones que no se contemplan en la negociación colectiva y existen medidas de promoción de carácter puntual y limitado, que se centran de forma estática en temas como la mejora de las licencias de maternidad y parental, así como en las licencias para el cuidado de la familia. En este sentido, la OIT ha destacado la labor de promoción de la igualdad de género realizada en el contexto de la Unión Europea a raíz de la Directiva 2002/73/CE, que ha dado lugar a un aumento de la negociación colectiva en el tratamiento de la igualdad de género en las legislaciones de los Estados miembros. Por ejemplo, en España desde la aprobación de la Directiva 2002/73/CE se ha producido un cambio significativo en la dinámica negociadora, ya que la Ley Orgánica 3/2007, de 22 de marzo, para la igualdad efectiva de mujeres y hombres, ha aumentado el ámbito de acción de la negociación colectiva y dicho cambio sustancial ha reforzado el propio diálogo social bipartito, puesto que el objetivo de la igualdad de género se ha venido incorporando desde el año 2002 en los Acuerdos de Negociación Colectiva (ANC) ${ }^{85}$. El objetivo no es otro que las trabajadoras puedan desarrollar su actividad profesional con la garantía del principio de igualdad de trabajo y de oportunidades. Ello significa abrir un espacio legalmente a la promoción de la negociación de la igualdad de género por medio de deber de negociar. Y reforzar el papel de la negociación colectiva de mejorar los contenidos legales, con reglas de derecho mínimo necesario, y complementar las normas básicas previstas legalmente.

Especialmente los sindicatos han realizado grandes esfuerzos en la lucha contra la brecha salarial por motivos de género mediante el diálogo social, convirtiendo dicho tema en un aspecto clave de la negociación colectiva. Ello, incluso, ha propiciado cambios organizativos en la propia naturaleza del sindicato, que ha tenido que adaptar sus propias estructuras orgánicas en busca de la especialización en temas de género. E, irremediablemente, dichos cambios internos han supuesto ineludiblemente un aumento considerable de la propia participación femenina en los sindicatos y, especialmente, en la acción sindical, lo cual ha supuesto su participación directa en el tratamiento y resolución de los problemas específicos en materia de género que se desarrollan en la dinámica de las relaciones laborales.

85. Si bien es cierto que los acuerdos colectivos sobre el teletrabajo son poco frecuentes, los sindicatos europeos han elaborado directrices para negociar con las empresas pactos relativos a la implantación del teletrabajo. 
Con todo, es indudable que el proceso depende en última instancia de la propia conciencia y responsabilidad empresarial a la hora de alcanzar el objetivo de la igualdad. En este sentido, conviene recordar las recomendaciones realizadas por la propia OIT en sus campañas de promoción del trabajo decente entre los empresarios. Precisamente, en este ámbito la responsabilidad social corporativa juega un papel esencial y puede dar respuesta, como ha indicado la propia OIT, a los desafíos planteados por un mercado de trabajo globalizado y, sin duda, la implicación empresarial en el modo de gestionar el trabajo puede repercutir cualitativamente en la propia sociedad. La responsabilidad social de las empresas se muestra como un aspecto potencial para promover la igualdad, aunque ciertamente se trata de medidas de carácter voluntario generalmente asumidas por las grandes empresas multinacionales, que adquieren compromisos desde un punto de vista de la ética empresarial, que rebasan el cumplimiento de las obligaciones previstas por los ordenamientos nacionales. Nos referimos a las medidas previstas en códigos de conducta, auditorías corporativas de gestión y recopilación de acciones que fomentan el cumplimiento de las legislaciones laborales y la ausencia de prácticas discriminatorias ${ }^{86}$. En este sentido, conviene decir que en la mayoría de los códigos de conducta de las grandes empresas multinacionales se contienen generalmente llamadas a la garantía de la no discriminación y la igualdad en el trabajo. Sin duda, el gran reto reside en introducir esta concepción empresarial de la promoción de la igualdad en las pequeñas y medianas empresas. Ciertamente, el problema en estos contextos empresariales reside en que en muchos casos la igualdad de género se aprecia como un problema que genera costes añadidos (sobre todo en relación a la igualdad de la remuneración), máxime cuando las medidas a favor de la igualdad no tienen una traducción directa desde la óptica empresarial en el aumento de la productividad.

\section{REFERENCIAS BIBLIOGRÁFICAS}

\section{Abramo, L - Todaro, R., (2002) Cuestionando un mito: costos laborales de hombres y mujeres en América Latina, OIT, Lima}

Anker, R., (2005) Women's access to occupations with authority, influence and Decision-Making Power, Departamento de Integración de Políticas, documento de trabajo núm. 44, Ginebra, OIT

86. Precisamente, la Ley Orgánica de Igualdad en España ha contemplado materias en las que se refuerza el deber de negociar, por ejemplo, el establecimiento de medidas de acción positivas para favorecer el acceso de las mujeres al empleo y la aplicación efectiva del principio de igualdad de trato y no discriminación (art. 43), la adopción de medidas que eviten cualquier tipo de discriminación entre hombres y mujeres (art. 45.1), el 
Awad, I., (2009), The global economic crisis and migrant workers: Impact and response, Ginebra, OIT,

Ballester Pastor, Ma.A., (2010), Conciliación laboral y familiar en la Unión Europea: rémoras, avances y nuevas líneas de tendencia en el ámbito de la corresponsabilidad", en Revista de Derecho Social, núm. 51, 2010.

Ballester Pastor, Ma.A., (2006), El principio comunitario de igualdad de trato por razón de origen racial o étnico", en Revista del Ministerio de Trabajo e Inmigración, núm. 63

Blau, F. - Kahn, L., (1996), Wage structure and gender earnings differentials: An international comparison, en Economica, Oxford, Blackwell Publishers, vol. 63, núm. 2503

Bolle, P., (1997), La licencia para el cuidado de los hijos, en Perspectivas. Revista Internacional del Trabajo, vol. 116, Ginebra, OIT, 1997.

Boulin, J.Y. - Lallement, M. - Michon, F., (2006), Decent working time in industrialized countries: Issues scopes and paradoxes, en Decent working Time: New Trends, new issues, Ginebra, OIT

Bourdieu, P., (1998), La domination masculine, Le Seuil, París

Bruegel, I. - Perrons, D., (1998), Deregulation and women's employment: The diverse experiences of women in Britain, en Feminist Economies, Londres, Routledge Journals, vol. 4, núm. 1, 1998.

Cabeza Pereiro, J., (2011) Las políticas de conciliación al servicio de la igualdad entre hombres y mujeres", en AAVV, Conciliación de la vida familiar y laboral y corresponsabilidad entre los sexos, Tirant lo Blanch, Valencia, 2011.

Comisión Europea, (2001), Gender Equality Magazine: Equal Pay, núm. 11, Publicaciones de la Comunidad Europea, Luxemburgo

Confederación Sindical Internacional, (2009), (Des)igualdad de género en el mercado laboral: Visión general de las tendencias y progresos mundiales, Bruselas 
Crush, J. - Ramachandran, S., (2009) Xenophobia, international migration and human development, Human Development Research Paper, 2009/47, PNUD

Dickens, L., (1998) Equal opportunities and collective bargaining in Europe.4. Illuminating the process (Luxemburgo, Oficina de Publicaciones Oficiales de las Comunidades Europeas

Fauroux, R.,(2005), La lutte contre les discriminations dans le domaine de l'emploi, Ministerio de Empleo, Cohesión Social y Vivienda, París

Fredman, S., (2008), Positive rights and duties: Addressing intersectionality, en D. Schiek y V. Chege (directores): European Union non-discrimination law: Comparative perspectives on multidimensional equality law, Londres, Routledge-Cavendish,

Gálvez, T, (2006), Discriminación de género en el mercado laboral de América Latina: La brecha de ingresos 2001", capítulo III, en L. Abramo (Dir.), Trabajo decente y equidad de género en América Latina, OIT, Santiago

García Murcia, J., (2006), Igualdad y no discriminación en las relaciones laborales, Las transformaciones del Derecho del Trabajo en el marco de la Constitución Española, Estudios en homenaje al profesor M. Rodríguez-Piñero y Bravo-Ferrer, La Ley, Madrid.

Gray, M.C. - Tudball, J., (2002), Family-friendly work practices: Difference within and between workplaces, Australian Institute of Family Studies Research Report, núm. 7, Melbourne

Gunderson, M., (2006), Viewpoint: Male-female wage differentials: How can that be?, en Canadian Journal of Economics, vol. 39, núm. 1

Harriman, A. - Holm, C., (2001) Steps to pay equity: An easy and quick method for the evaluation of work demands, Equal Opportunities Ombudsman.

Harriss-White, B., (2003), La desigualdad en el trabajo en la economía informal. Cuestiones esenciales y ejemplos, en Revista Internacional del Trabajo, Vol. 122, núm. 4. 
Haspels, N. - Kasim, Z.M. - Thomas, C. - Mccann, D., (2001) Action against sexual harassment at work in Asia and the Pacific, OIT, Bangkok

Hein, C., (2005), Reconciling work and family responsibilities: Practical ideas from global experience, Ginebra, OIT

Hein, C-Cassirer, N., (2010), Soluciones para el cuidado infantil en el lugar de trabajo, Ginebra, OIT

Hepple, B., (2011), Equality: The New Legal Framework, Hart Publishing

Heymann, J., (2006), Forgotten Families: Ending the growing crisis confronting children and working parents in the global economy, Nueva York, Oxford University Press

Instituto Internacional de Estudios Laborales, (2009) Informe sobre el Trabajo en el Mundo 2010: ¿De una crisis a la siguiente?, Ginebra.

JJE, (2006), United Nations system-wide policy on gender equality and the empowerment of women: focusing on results and impact, $\mathrm{CEB}$ /2006/2, 15 de diciembre de 2006.

Jolidon, G., (2001), La lutte contre la discrimination dans l'emploi et la profession par le biais des conventions collectives de travail, documento preparado para el Programa InFocus sobre la Promoción de la Declaración, Ginebra, OIT, 2001.

Katz, C. - Baitsch, C.,(1996), L' égalité des salaires en pratique: Deux outils d' évaluation du travail non discriminatoire à l' égard des sexes, VDF y Georg Editeur, Ginebra.

Kirkwood, E. - Malhotra, D.,(2010), Economic opportunities for women in the East Asia and Pacific Region, Washington, D.C., Banco Mundial,

Macdermind, S.M. - Litchfield, L.C. - Pitt-Catsouphes, M., (1999), Organizational size and workfamiliy issues", en Annals of the American Academy of Political and Social Science, vol. 562.

OCDE, (2010), Gender Brief, OECD Social Policy Division. 
OCDE, (2002), Perspectivas del empleo, París

OIE, Trabajo decente. Cómo llevarlo a la práctica: el punto de vista de los empresarios, Ginebra, 2002.

OIT, (1998), Igualdaden el empleo y la ocupación, Estudio General.

OIT (2001), Informe de la Comisión de Expertos en Aplicación de Convenios y Recomendaciones, Informe III (1A), 89. reunión de la Conferencia Internacional del Trabajo, Ginebra

OIT, (2002), El trabajo decente y la economía informal, Conferencia

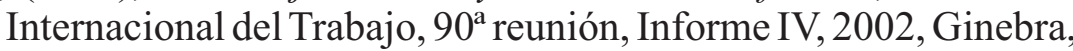

OIT, (2003) La hora de la igualdad en el trabajo, Conferencia Internacional del Trabajo, $91^{\mathrm{a}}$ reunión, Ginebra.

OIT, (2006), Igualdad de género y trabajo decente, Ginebra

OIT, (2006), Trabajo decente y equidad de género en América Latina, Santiago.

OIT, (2007), La igualdad en el trabajo: afrontar los retos que se plantean, Conferencia Internacional del Trabajo, 96 ${ }^{\mathrm{a}}$ reunión, Ginebra.

OIT, (2007), Informe de la Comisión de Cooperación Técnica, Consejo deAdministración, 300. ${ }^{a}$ reunión, documento GB.300/TC/4, Ginebra.

OIT, (2007), Seguimiento de la Declaración de la OIT relativa a los principios y derechos fundamentales en el trabajo: prioridades y programas de acción para la cooperación técnica relativa a la eliminación de la discriminación en materia de empleo y ocupación. Informe de la Comisión de Cooperación Técnica. Documento GB.300/TC /4, Consejo de Administración, 300. . reunión, Ginebra.

OIT, (2008), Declaración de la OIT sobre la justicia social para una globalización equitativa, adoptada por la Conferencia Internacional del Trabajo en su 97. ${ }^{a}$ reunión, Ginebra.

OIT, (2008), Guía práctica para la incorporación sistemática del empleo y el trabajo decente. Aplicación a nivel de país, Ginebra. 
OIT, (2009), La igualdad de género como eje del trabajo decente, Conferencia Internacional del Trabajo, $98^{\text {a }}$ Reunión, Ginebra

OIT, (2009), La igualdad de género en el corazón del trabajo decente", en Trabajo Revista de la OIT, núm. 65

OIT, (2009) Trabajo decente, vida decente para la mujer, Primera Conferencia Mundial sobre la mujer, Bruselas

OIT, (2009) Informe de la Comisión de la Igualdad de Género, Resolución relativa a la igualdad de género como eje del trabajo decente, Actas Provisionales núm. 13, Conferencia Internacional del Trabajo, 98. ${ }^{a}$ reunión, Ginebra

OIT, (2009) Informe mundial sobre salarios: Actualización 2009, Ginebra.

OIT, (2009)Para recuperarse de la crisis: Un Pacto Mundial para el Empleo, Conferencia Internacional del Trabajo, 98. ${ }^{a}$ reunión, Ginebra

OIT, (2009) Propuesta revisada de la Oficina para la medición del trabajo decente basada en las orientaciones recibidas en la Reunión tripartita de expertos sobre la medición del trabajo decente, Departamento de Integración de Políticas, Ginebra.

OIT, (2010), Tendencias mundiales del empleo juvenil, publicación especial sobre la incidencia de la crisis económica global en los jóvenes, Ginebra

OIT, (2010), Plan de acción de la OIT sobre igualdad de género 20102015. Fase I: Armonizada con el Programa y Presupuesto para el bienio 2010-2011, Oficina Internacional del Trabajo, Ginebra

OIT, (2010), La maternidad en el trabajo. Examen de la legislación nacional. Resultados de la base de datos de la OIT sobre las leyes relacionadas a las condiciones de trabajo y de empleo, segunda edición, Ginebra

OIT, (2011), La igualdad en el trabajo: un objetivo que sigue pendiente de cumplirse, Conferencia Internacional del Trabajo, 100 a reunión, Ginebra, 2011. 
OIT-IIEL, (2009), Informe sobre el trabajo en el mundo 2009. Crisis mundial del empleo y perspectivas, Ginebra.

Organización de los Estados Americanos (2007), (Consejo Interamericano para el desarrollo integral), Lineas estratégicas para avanzar hacia la igualdad y no discriminación de género en el marco del trabajo decente, XV Conferencia Interamericana de Ministros de Trabajo, Puerto España.

Papademetiou, D. - Sumption, M. - Terrazas, A.,(2010), Migration and immigrants two years after the financial collapse: Where do we stand? BBC World Service, Migration Policy Institute.

Pérez Del Río, $M^{a}$.T., (1997), El principio de igualdad de trato y la prohibición de discriminación por razón de sexo en el derecho comunitario, en Cuadernos de Derecho Judicial, núm. 10

Pérez Del Río, Ma ${ }^{\mathrm{a}}$.T., (1984), El principio de igualdad: no discriminación por razón de sexo en el Derecho del Trabajo, Ministerio de Trabajo y Seguridad Social, Madrid.

Pérez Del Río, Ma.T., (2005), El acervo comunitario en materia de igualdad de trabajo: la adecuación del ordenamiento jurídico interno", Aequalitas, Revista Jurídica de igualdad de oportunidades entre mujeres y hombres, núm. 16

Perotin, V. - Robinson, A. - Loundes, J.,(2002), Equal opportunities practices and performance in small and medium-sized enterprises: Preliminary findings, Ginebra, OIT.

Pillinger, J.,(2002), Equité salariale, maintenant! Dossier d'information sur l'équité Salariale, ISP, Bruselas.

Puhl, R.M. - Andreyeva, T. - Brownell, K.D., (2008), Perceptions of weight discrimination: Prevalence and comparison to race and gender discrimination in America", International Journal of Obesity, núm. 32

Reinhart, A., (1999), Sexual Harassment, addressing sexual harassment in the workplace. A management information booklet, OIT, Ginebra

Rodríguez-Piñero Y Bravo Ferrer, M. - Rodríguez-Piñero Royo, M.C., (2004), The principle of equality in the labour market: reflections 
on the spanish model, Essays in honour of Georgios I. Kassimatis, (Coord. Nikolaos Alvizatos), Ed. BWV Berliner WissenshaftsBruylant, Atenas

Rodríguez-Piñero Y Bravo Ferrer, M., (1991), El principio de igualdad en la Constitución española: XI Jornadas de Estudio, Vol 2, 1991, Ministerio de Justicia, pp. 1070-1071.

Rodríguez-Piñero Y Bravo Ferrer, M., (1983), No discriminación en las relaciones laborales" en AAVV, Comentarios al Estatuto de los Trabajadores, Madrid: Edersa, vol. IV

Rooth, D., (2007), Evidence of unequal treatment in hiring against obese applicants: A field experiment, Institute for the Study of Labor

Ruggie, J., (2006), Human Rights Policies and Management Practices of Fortune Global 500 Firms: Results of a Survey, núm. 28 sobre la responsabilidad social de la empresa, Universidad de Harvard, John F. Kennedy School of Government.

Tomei, M., (2000), Home work in selected Latin American countries: A comparative overview, OIT, Ginebra.

Wirth, L.,(2000), Breaking through the glass ceiling: women in management, OIT, Ginebra, 2001. UNIFEM, El progreso de las mujeres en el mundo 2000, Informe bienal de UNIFEM, Nueva York 